\title{
ENTRE EL BRONCE FINAL Y EL HIERRO ANTIGUO. LAS CERÁMICAS A MANO DE LA SOLANA DEL CASTELL (XÀTIVA, VALÈNCIA)
}

\author{
BETWEEN THE LATE BRONZE AGE AND THE EARLY IRON AGE. HANDMADE POTTERY IN \\ LA SOLANA DEL CASTELL (XÀTIVA, VALÈNCIA)
}

JOSÉ PÉREZ BALLESTER

Universitat de València ${ }^{1}$

\section{INTRODUCCIÓN}

El yacimiento que nos ocupa reúne rasgos generales que caracterizan a los asentamientos del Bronce Final en tierras valencianas (Gil Mascarell, 1981; Martí y De Pedro, 1997; Hernández, 2005; Vives Ferrándiz, 2006): son asentamientos de nueva creación, ubicados preferentemente en ladera y cerca de vías de comunicación. En ellos, se documenta la presencia de intercambios con la Meseta (Cultura de Cogotas $\mathrm{I}^{2}$, Valle del Ebro y Cataluña (Grupos de Campos de Urnas ${ }^{3}$ ), Andalucía y el Mediterráneo, a veces reflejada en elementos manufacturados de prestigio, incluso de origen ultramarino, que en nuestro caso se traduce en la presencia de un brazalete de marfil, una perla de ámbar, ésta posiblemente de origen peninsular, o una fíbula de pivote entre otros (Pérez Ballester et alii, 2011).

En cuanto al Hierro Antiguo (estado de la cuestión en Vives Ferrándiz, 2006; Hernández, 2005, 24-25), desde finales del s. VIII a la primera mitad del s. VI encontramos junto a una continuidad de los hábitats del Bronce Final, la aparición de nuevos asentamientos en la línea de costa, en relación con la presencia directa o indirecta de gentes fenicias occidentales: La Fonteta (Guardamar, Alicante), Alt de Benimaquia

1. Este trabajo se ha realizado en el marco del proyecto HAR20112-32488, «Cerdeña e Ibiza: la ocupación rural en época púnica».

2. Por la cronología del Bronce Final del País Valenciano, estaríamos en los últimos momentos de Cogotas I, o en lo que Ruiz Zapatero llama los «Grupos de transición Bronce Final - Hierro» (Ruiz Zapatero, 2007, 40-42; Abarquero, 2005, 302-303).

3. Para una actualización de los Campos de Urnas en Cataluña y Aragón, en relación con el Bronce Final y Primera Edad del Hierro en esas regiones, con la discusión sobre la cronología en base a fechas calibradas, véanse los trabajos de López Cachero, 2006 y López Cachero y Pons, 2007. Conociendo estas tablas, seguiremos utilizando por comodidad la clasificación de Ruiz Zapatero, 1985.
(Dénia, Alicante) y seguramente el Altet de la Vintihuitena (Albalat, València), en la desembocadura del Xúquer; este último yacimiento, en contacto con La Solana, como luego veremos. A nivel cultural como es sabido, los cambios son muy importantes: introducción de la metalurgia del hierro, de la cerámica a torno, el cultivo de frutales: vid, olivo, almendro, y el aumento del ganado tabulado: ovicápridos principalmente, pero también bóvidos (Pérez, Iborra, Grau, Bonet y Mata, 2000, 157; Iborra, 2004). En cuanto al comercio, es frecuente la presencia de cerámicas importadas de origen fenicio occidental: ánforas de vino tipo R-1, pithoi, morteros trípodes, y vajilla de barniz rojo o gris, cerámicas pintadas, fíbulas de doble resorte, etc., que penetran hasta $100 \mathrm{~km}$ al interior (Vives Ferrándiz, 2006, 149-159).

\section{LA SOLANA DEL CASTELL (Fig. 1)}

La actual ciudad de Xàtiva se encuentra en el extremo más nordoriental de la Serra Grossa, que desde la Font de la Figuera delimita por el sur el Valle del Canyoles. Su excepcional ubicación, ofrece a la vez una

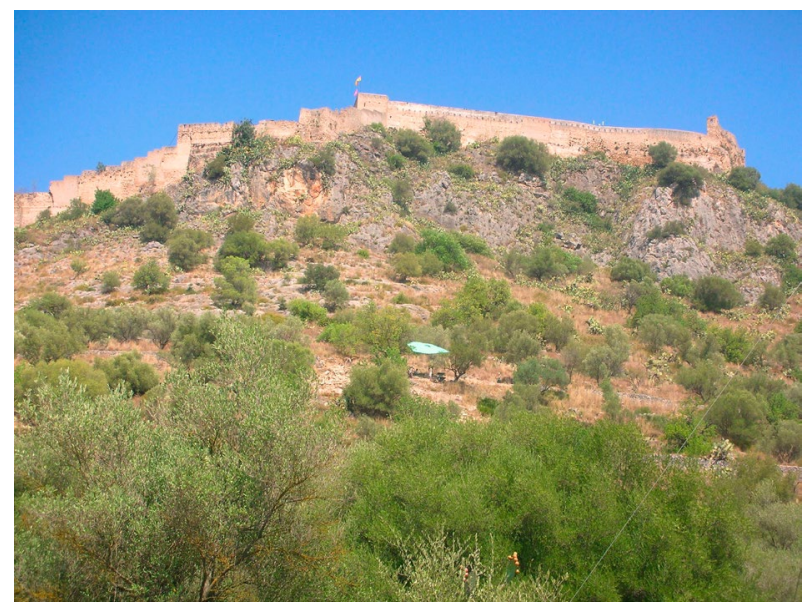

Figura 1: La Solana del Castell, bajo el Castell Menor. 


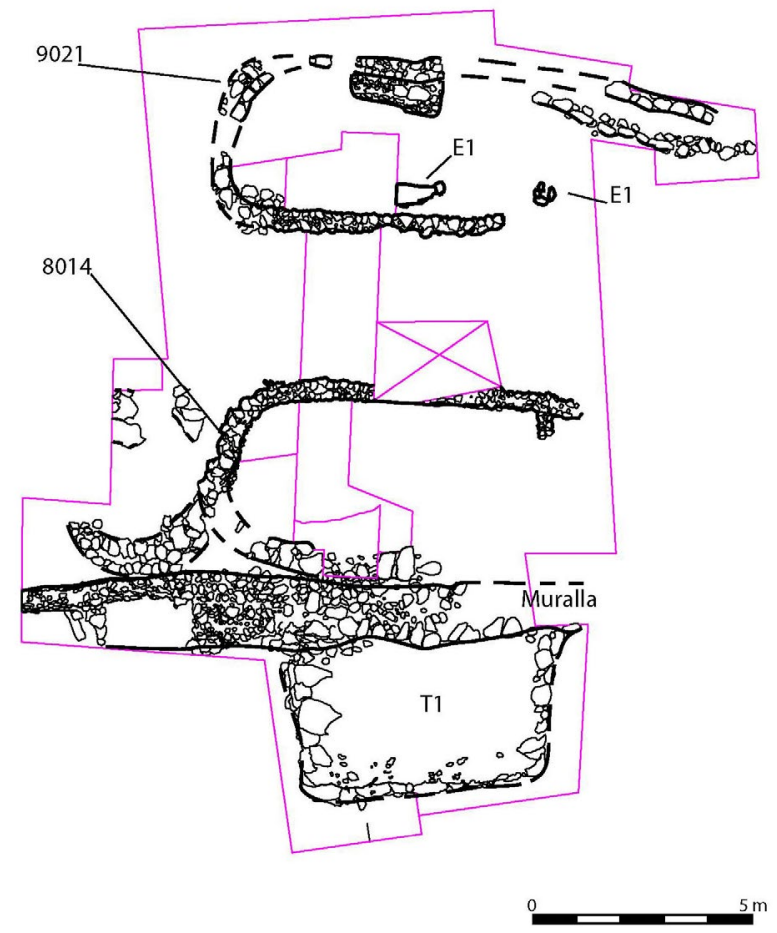

Figura 2: La Solana. Planta de estructuras del Sector E-3. E-1: estructuras de Solana I. 8014 y 9021: casas absidadas (Solana II/III). Muralla y Torre 1 (Solana II/III).

protección natural y un control de la vía natural que siguiendo el Valle del Canyoles comunica, una vez cruzado el Xúquer, las planicies litorales valencianas con la Meseta. Su ubicación cerca del Estret de les Aigües, garganta del río Albaida, le permite controlar a su vez el paso hacia las comarcas interiores valencianas y alicantinas. A nivel macroterritorial, podríamos decir que ocupa una posición de «bisagra» entre el Valle del Vinalopó y las tierras valencianas al norte del Xúquer.

El poblamiento antiguo de Xàtiva se localiza a una y otra vertiente de la cresta caliza que corona la Serra del Castell: hacia el sudeste, La Solana, y hacia el noroeste La Costa, al pie de la cual se extiende la ciudad actual. La cresta caliza se interrumpe en un trecho central, abriendo la posibilidad de que fuese allí donde conectasen ambas zonas habitables del antiguo asentamiento de la Saitabi ibérica. Las excavaciones iniciadas en el año 2006 en el paraje de La Solana, (Pérez Ballester et alii, 2008, 2009, 2010, 2011, 2013), nos revelaron un hábitat aterrazado, con niveles y estructuras del Ibérico Pleno y Tardío, (la Saitabi ibérica) y por debajo otros más antiguos, que llegan hasta el Bronce Final. Los materiales y estructuras hallados, como ahora veremos, nos permiten afirmar que hubo una continuidad del poblamiento en La Solana del Castell, desde los siglos X-IX al I a.C. Su extensión no es segura, debido a la fuerte erosión de la mitad superior de la ladera; prudentemente, podemos estimarla en al menos $2 \mathrm{Ha}$.

Hasta 2013, la superficie excavada es de unos 300 $\mathrm{m}^{2}$. El Sector E-3 es el que nos ha proporcionado una secuencia más completa, desarrollada en cuatro terrazas superpuestas: Bronce Final (Solana I y II), Hierro Antiguo (Solana III), Ibérico Antiguo (Solana IV) e Iberico Pleno/Tardío (Solana V).

\section{EL BRONCE FINALY EL HIERRO ANTIGUO}

Fase Solana I (SC-I). Las únicas estructuras conservadas consisten en parte de un murete de tapial $(1 \mathrm{~m})$ y las bases de dos postes separados por $2,5 \mathrm{~m}$, colocados sobre una preparación de la roca natural (Fig. 2). A esta misma fase hemos adscrito los rellenos de terraplenes y obras de acondicionamiento de la ladera, anteriores a la construcción de las estructuras que ahora mencionaremos. Los materiales cerámicos que presenta, son a mano.

Está datada por C14 sobre colágeno de dos restos óseos de ovicápridos (Beta Analytic 7/31/2013):

\begin{tabular}{|l|}
\hline Datos Edad Radiocarbónica Convencional \\
\hline Beta-354228 2740+/-30 BP \\
SC / 11008-1 \\
Calibración 2 Sigma: 970 a 960 cal BC y 930 a 820 \\
cal BC \\
\hline Beta-354230 2640+/-30 BP \\
SC / 11023-1 \\
Calibración 2 Sigma: 830 a 790 cal BC \\
\hline
\end{tabular}

Fase Solana II (SC-II). Niveles y estructuras sobre los terraplenes, consistentes en:

- Dos grandes habitaciones absidadas, construídas en piedra y tapial (Fig. 2). Se sitúan en paralelo en las Terrazas $2^{\mathrm{a}}$ y $4^{\mathrm{a}}$, y han perdido su extremo oriental por la erosión. Sus dimensiones son similares: una anchura de $3 \mathrm{~m}$ y una longitud conservada que oscila entre 13/ 7,5 m (muros paralelos de la estructura 9021) y 9,5 / 5,5 m (muros paralelos de la estructura 8014). Esta última presenta, cerca de su extremo Este, parte de un murete de orientación N/S que compartimenta el espacio. En la habitación absidada 8014 se conservaron dos pavimentos, el inferior con parte de un hogar rodeado de conchas marinas, y asociado sólo a cerámicas a mano.

- Muralla y torre 1 (Fig. 2). La muralla tiene una anchura de 1,5 $\mathrm{m}$ y un alzado conservado en piedra de un metro. Se levanta sobre una terraza o talud de unos 2,5 m de altura. En este Sector E-3 se conserva en unos $12 \mathrm{~m}$ de longitud. En W-3, a $80 \mathrm{~m}$ de la anterior, otros $17 \mathrm{~m}$. La torre, de 4 x $6 \mathrm{~m}$ de planta y un alzado conservado de $2,5 \mathrm{~m}$, está construída con grandes piedras, y se adosa al terraplén sobre el que se levanta la muralla.

Sin cerámicas a torno, aún no tenemos fechas radiocarbónicas, pero su situación sobre los niveles más antiguos (Solana I), los cambios en las estructuras y las ligeras diferencias en la tipología de las cerámicas que ahora veremos, nos hacen pensar en una fase 
diferente y algo más moderna que la anterior (aprox. S. VIII a.C.).

Al Hierro Antiguo, o Solana III (SC-III), corresponden:

- El segundo momento de ocupación de las casas absidadas

- Quizás la edificación de la torre 1 en E-3

- En E-4, unos 20 m al Este de E-3, la construcción de otras dos estructuras de habitación en piedra con restos de adobes, muy destruídas por la erosión. Los materiales incluyen junto a cerámicas a mano mayoritarias, un 10-20\% de cerámicas a torno en su mayoría fenicias occidentales, así como algún pequeño fragmento de hierro y escorias del mismo metal.

No poseemos aún dataciones radiocarbónicas, pero podemos fechar esta Fase entre inicios del s. VII y la $1^{\mathrm{a}}$ mitad del s. VI a.C., por el material cerámico.

\section{LAS CERÁMICAS A MANO DE LA SOLANA}

Hasta la campaña de 2012 hemos inventariado un total de 13.249 fragmentos a mano, pertenecientes a un NMI de 1.542 piezas, de las que 1.105 han sido susceptibles de estudio tipológico: 600 piezas cuidadas y 505 toscas. Al Bronce Final corresponden 579 ejemplares y al Hierro Antiguo 202. El resto se hallaron en niveles del Ibérico Antiguo (64 ejs.) o revueltos (260 ejs.).

Las cerámicas a mano cuidadas tienen pastas generalmente de color negro, alguna vez grises y excepcionalmente de color castaño anaranjado. El grano es fino, y los desgrasantes más frecuentes son cristales de calcita. La superficie es de coloración uniforme, negra o gris oscuro, con tratamiento generalmente bruñido y ocasionalmente espatulado.

Las cerámicas a mano toscas tienen pastas de grano más grueso, con desgrasantes variados, entre los que destacan los cristales de calcita y gránulos de arenas. Excepcionalmente hemos documentado huesos machacados añadidos como desgrasante. Tiene casi siempre cocción alterna y suele ser de color castaño hacia la superficie, con manchas más claras u oscuras. El acabado es generalmente alisado y a veces grosero.

\section{LA TIPOLOGÍA ${ }^{4}$}

Para realizar nuestra tipología nos fue muy útil el trabajo de Lorrio sobre las necrópolis del sureste en el Bronce Final (2008), la tipología de González Prats sobre Peña Negra (1982 y 1985) y la más reciente de García Borja y Pérez Jordá (2012), a la que referiremos la nuestra siempre que sea posible. Así mismo, hemos consultado para la Fase Solana III la de Ortiz Temprado (2014) sobre La Fonteta.

4. Agradecemos la inestimable colaboración de nuestro colega J.A. Rodríguez Traver en el desarrollo de este apartado.
La clasificación que presentamos es sencilla, en el sentido de que hemos acudido a una clasificación funcional, ordenando las formas según fuesen vasos más o menos abiertos o cerrados, y más o menos profundos, con la ayuda de los parámetros métricos diámetro del borde $(\mathrm{Db})$ e índice rdp, resultante de dividir el diámetro del vaso por la profundidad del mismo. Diferentes variantes de borde o cuello definen los subtipos dentro de cada forma. Todas estas características pueden condicionar el uso del recipiente, combinado con su tamaño y su acabado.

Como vemos en el listado que adjuntamos a continuación, en la cerámica cuidada, el grupo C-I refiere a platos y páteras; C-II a $\mathrm{V}$ y sus variantes agrupan a distintos tipos de formas abiertas: cuencos o copas, cazuelas o fuentes, con uso preferente para consumir o servir alimentos; la C-VI agrupa a recipientes cerrados cuyo mayor diámetro está en el cuerpo del vaso; las CVII y VIII a grandes vasijas profundas, funcionalmente relacionadas con el almacenamiento de alimentos.

Entre las cerámicas toscas, T- I corresponde a páteras o platos; T-II y III y sus variantes son cuencos o copas, cazuelas o fuentes; T- IV son ollas, grupo especialmente importante en esta clase de cerámicas; $\mathrm{T}-\mathrm{V}$, VI, VII y VIII son grandes recipientes para almacenaje; y T-IX está reservado a «otras»; en nuestro caso T-IX-1 se corresponde con un soporte o carrete.

\section{Cerámicas Cuidadas}

\section{C-I: Platos y páteras}

C-I -1 (Fig. 3): Plato de paredes tensas y borde exvasado que forma un perfil en «S» con el cuerpo del vaso. Ejemplar único. Db: $13 \mathrm{~cm}$; rdp: 2,8. Aprox. forma G.3.II.b de García Borja y Pérez Jordá, 2012.

\section{C-II: Cuencos}

C-II-1 (Fig. 3): Cuenco simple de casquete esférico. Formato pequeño: $\mathrm{Db}: 8-14 \mathrm{~cm}$ y $\mathrm{rdp}=1,7 / 2$; formato mayor, $\mathrm{Db}: 18-30 \mathrm{~cm}$ y $\mathrm{rdp}=2,8 / 3,2$.

Aprox. G.6.I.a (labio redondeado) o G.6.I.f (labio biselado) de García Borja y Pérez Jordá, 2012.

C-II-2 (Fig. 3): Cuenco de borde reentrante. Db: 15/20 cm; rdp: 1,5/1,75.

Aprox. G.7. II.a de García Borja y Pérez Jordá, 2012.

C-II-3 (Fig. 3): Cuenco de borde recto. Db: 11-18 cm; rdp: $1,4 / 2,2$.

Aprox. G.8.I.a de García Borja y Pérez Jordá, 2012.

C-II-4 (Fig. 3): Cuenco de borde exvasado, con clara inflexión en la parte superior de la pared. $\mathrm{Db}$ : 10/16 cm; rdp: $2 / 3$.

Aprox. G.3.III.b de García Borja y Pérez Jordá, 2012. 


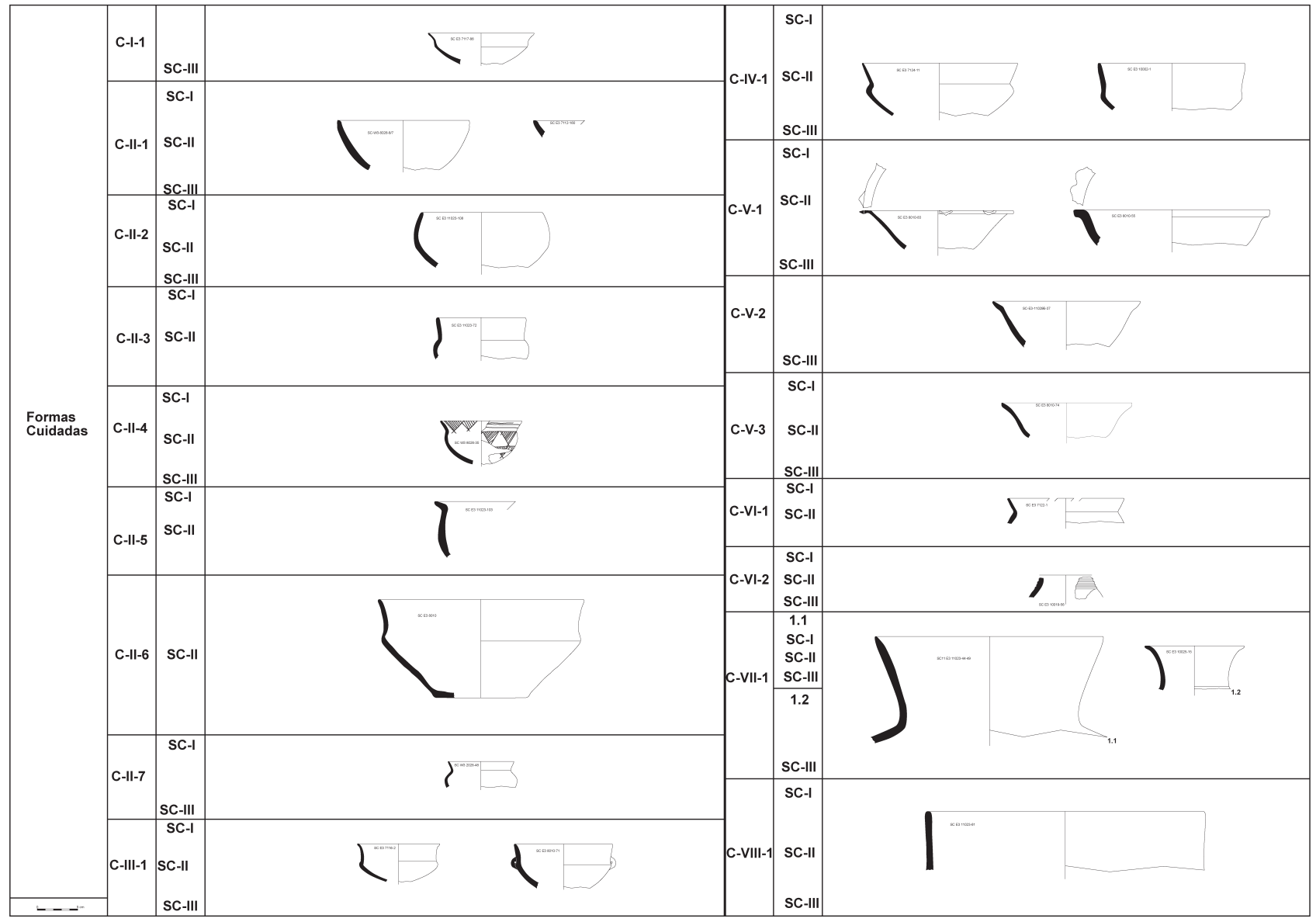

Figura 3: Tipología. Cerámicas Cuidadas.

C-II-5 (Fig. 3): Cuenco profundo de borde indicado exvasado. Muy incompleto.

C-II-6 (Fig. 3): Gran cuenco carenado de borde recto y cuerpo troncocónico. Ejemplar único. Db: $25 \mathrm{~cm}$; rdp: 1,7 .

C-II-7 (Fig. 3): Cuenco de perfil en «S». Db: 8-14 cm; rdp: $1,7 / 2$.

Aprox. G.8.IV.b de García Borja y Pérez Jordá, 2012.

\section{C-III: Copas carenadas}

C-III-1 (Fig. 3): Cuencos/Copas carenadas. Db: 7-14 $\mathrm{cm} ; \mathrm{rdp}: 1,8 / 2,3$.

Aprox. G.3 de García Borja y Pérez Jordá, 2012.

\section{C-IV: Cazuelas carenadas}

C-IV-1 (Fig. 3): Cazuelas con carena más o menos marcada y borde exvasado. Dos formatos, medio, Db: $16-20$ y $\mathrm{rdp}=1,8 / 2$ y grande, Db: 22-38 cm y $\mathrm{rdp}=2,3 / 3$.

Aprox. G.3.II y G.5.I de García Borja y Pérez Jordá, 2012.

\section{$C-V:$ Fuentes}

C-V-1 (Fig. 3): Fuentes de borde horizontal lobulado. Db: $22 / 26 \mathrm{~cm} ; \mathrm{rdp}=3,1 / 4,3$.

Aprox. G.2.I de García Borja y Pérez Jordá, 2012. C-V-2 (Fig. 3): Fuentes de borde indicado exvasado. $\mathrm{Db}: 18 \mathrm{~cm} ; \mathrm{rdp}=2,4$.

C-V-3 (Fig. 3): Fuentes de perfil cóncavo-convexo. Db: 16 ; rdp: 3,5 .

Aprox. G.3.IIIa de García Borja y Pérez Jordá, 2012.

\section{C-VI: Ollas}

C-VI-1 (Fig. 3): Olla globular de borde exvasado y cuello estrangulado. Db y rdp indet. 


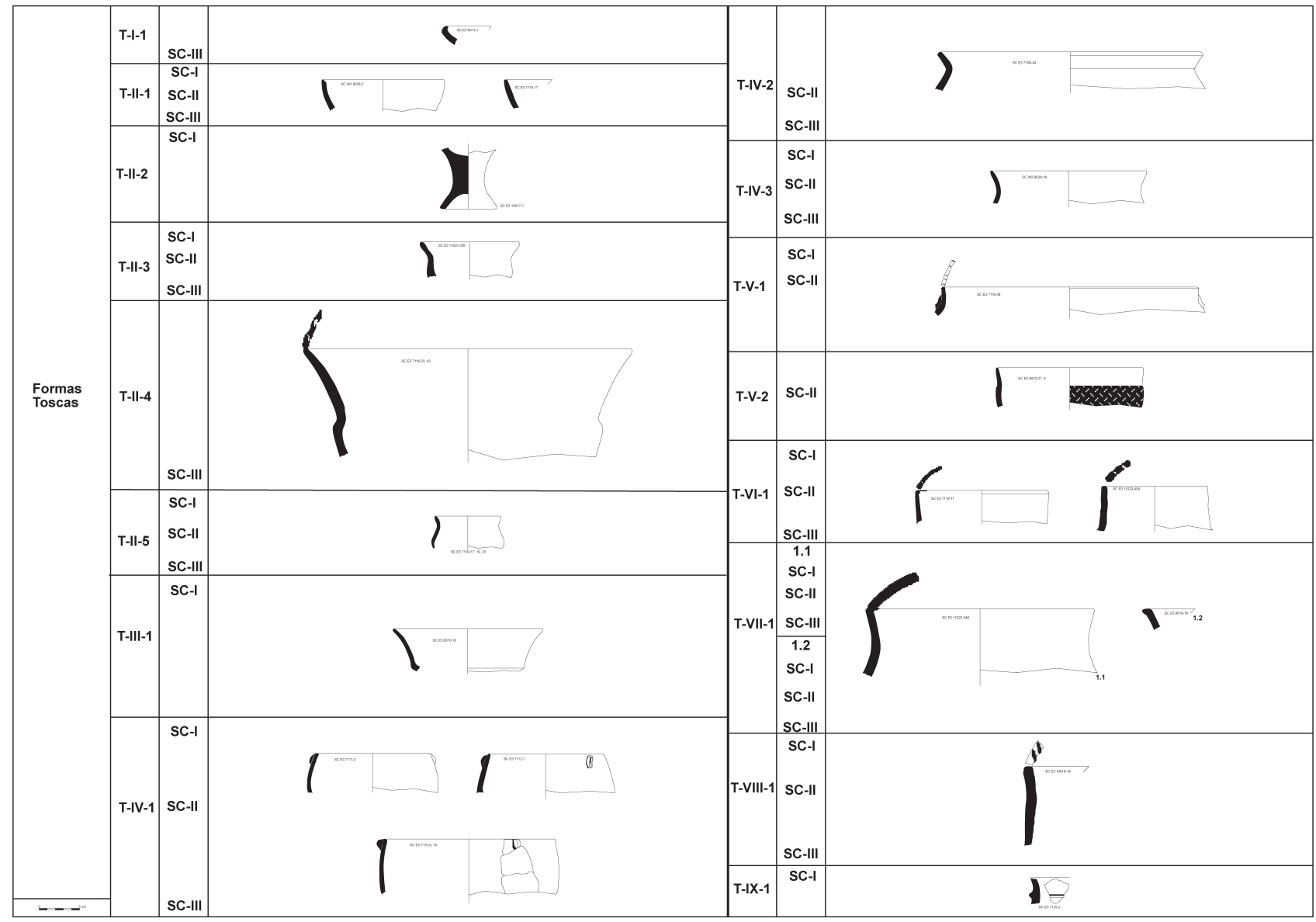

Figura 4: Tipología. Cerámicas Toscas.

Aprox. forma G.14.III.c de García Borja y Pérez Jordá, 2012.

C-VI-2 (Fig. 3): Olla bitroncocónica.

\section{C-VII: Vasijas de cuello exvasado}

C-VII-1.1 (Fig. 3): Vasija profunda de cuello destacado exvasado. Db: $26 / 40 \mathrm{~cm}$; rdp: \pm 1 .

C-VII-1.2 (Fig. 3): Vaso «à Chardon»: Db: 12-16 cm; rdp: \pm 1 .

\section{C-VIII: Vaso profundo de paredes verticales}

C-VIII-1 (Fig. 3): ¿Gran vasija cilíndrica?. Db: 30/40 cm; rdp: $<1$.

Aprox. forma G.15.I/II de García Borja y Pérez Jordá, 2012.

\section{Cerámicas Toscas}

\section{T-I: Platos / Páteras}

T-I-1 (Fig. 4): Pátera de borde reentrante. Db: indet; rdp: aprox. 4. Podría ser también una copa con pie alto, como vemos en la reciente tipología de La Fonteta (Ortiz, 2014). En caso contrario, se aproxima a la forma G.1.II de García Borja y Pérez Jordá, 2012.

\section{T-II: Cuencos}

T-II-1 (Fig. 4): Cuenco simple de casquete esférico. Como C-II-1. Dos formatos, medio Db: 13/16 y rdp: 1,6/2 y grande, $\mathrm{Db}: 22 / 26 \mathrm{~cm}$ y rdp: $3 / 4$.

Aprox. forma G.6.I.a (labio redondeado) o G.6.I.f (labio biselado) de García Borja y Pérez Jordá, 2012.

T-II-2 (Fig. 4): Cuenco-copa de pie alto. Ejemplar único. Db y rdp indet.

Aprox. forma G.19.I de García Borja y Pérez Jordá, 2012.

T-II-3 (Fig. 4): Cuenco de borde exvasado. Db: 12-20; rdp: $1,7 / 2$.

Aprox. G.3.I de García Borja y Pérez Jordá, 2012.

T-II-4 (Fig. 4): Gran cuenco carenado. Db: 40 cm; rdp: 1,8 .

T-II-5 (Fig. 4): Cuenco de perfil en «S». Semejante a C-II-7. Db: 8-10; rdp: 1

Aprox. forma G.8.IV.b de García Borja y Pérez Jordá, 2012. 


\section{T-III: Cazuelas carenadas}

T-III-1 (Fig. 4): Fuente o cazuela carenada. Ejemplar único. $\mathrm{Db}: 18 \mathrm{~cm}$; rdp: 2,4 Aprox. forma G.3.II.b de García Borja y Pérez Jordá, 2012.

\section{T-IV: Ollas}

T-IV-1 (Fig. 4): Olla globular de borde reentrante. Dos formatos, pequeño $\mathrm{Db}$ : 7/10 y grande $\mathrm{Db}: 22 / 23$ $\mathrm{cm}$, ambos con la misma rdp: 1/1,2.

Aprox. forma G.14.II de García Borja y Pérez Jordá, 2012.

T-IV-2 (Fig. 4): Olla de borde exvasado «estrangulado». Similar a C-VI-1. Db: 18/25 cm; rdp: 1,6.

Aprox. forma G.14.III.c de de García Borja y Pérez Jordá, 2012.

T-IV-3 (Fig. 4): Olla de borde exvasado continuo. Db: $10-20 \mathrm{~cm} ; \mathrm{rdp}: \pm 1,2 / 1,6$.

Aprox. forma G.14.III.b de García Borja y Pérez Jordá, 2012.

\section{T-V: Vasijas de borde destacado recto}

T-V-1 (Fig. 4): Gran vasija de borde recto. Db: 17-31 cm; rdp: indet.

Aprox. forma G.14.III.a de García Borja y Pérez Jordá, 2012.

T-V-2 (Fig. 4): Vaso profundo no globular de borde recto diferenciado por escalón o listel. Ejemplar único. $\mathrm{Db}: 18 \mathrm{~cm}$; rdp: 1,2.

\section{T-VI: Vasijas de cuello destacado recto}

T-VI-1 (Fig. 4): Vasija de cuello destacado recto. Dos formatos, medio Db: 16/20 y grande, Db: 24/35 $\mathrm{cm}$. Rdp: indet.

Aprox. G.12.IIa o G.15.IIIa de García Borja y Pérez Jordá, 2012.

\section{T-VII: Vasijas de cuello destacado exvasado}

T-VII-1.1 (Fig. 4): Vasija de cuello destacado exvasado y borde recto. $\mathrm{Db}: 14 / 18-22 / 28 \mathrm{~cm}$. Rdp: indet. Aprox. forma G.14.III.b de García Borja y Pérez Jordá, 2012.

T-VII-1.2 (Fig. 4): Vasija de cuello destacado exvasado $\mathrm{y}$ borde engrosado al exterior. $\mathrm{Db}$ : indet. $\mathrm{Rdp}$ : indet.

\section{T-VIII: Vasos profundos de paredes verticales}

T-VIII-1 (Fig. 4): ¿Gran vasija cilíndrica? Como CVIII-1. Db: 24-32 cm; rdp: $<1$.
Aprox. forma G.15.I/II de de García Borja y Pérez Jordá, 2012.

\section{T-IX: Otros}

T-IX-1 (Fig. 4): Soporte o carrete. Ejemplar único.

\section{LaS CERÁmicas de la faSe Solana I}

\section{Cerámicas Cuidadas (Fig. 5)}

Son un NMI de 239 piezas estudiadas pertenecientes a 15 formas distintas, de las que cinco de ellas: C-II-1, C-II-2 y C-II-4 (cuencos) y C-III-1 y C-IV-1 (copas y cazuelas carenadas) constituyen el $86,03 \%$ del del total de formas reconstruíbles.

Entre los cuencos, los 28 ejemplares de C-II-1 de perfil más simple, nos remiten a tradiciones anteriores que vienen desde los orígenes de la Edad del Bronce. Se documentan en todo el País Valenciano a veces con decoraciones incisas, que se extienden hasta el Hierro Antiguo: Tossal de Sant Miquel de Llíria, Requena, Mola d'Agres, Puig d'Alcoi, Peña Negra, etc. (Bonet Rosado, 1995, 122-124 y Lám. II; Peña Sánchez et alii, 1996, 53; Martínez García et alii, 2001, 125, fig. 5; Grau Mira y Segura Martí, 2012, 80-81). El hecho de presentar el extremo del borde biselado por el interior no parece un indicio de evolución formal, pues lo encontramos en las tres fases estudiadas. Los de borde reentrante C-II-2 los documentamos desde el Bronce Tardío de Orpesa la Vella (Castelló) o La Illeta des Banyets, con paralelos en el área granadina o en ambientes meseteños de Cogotas I (Barrachina Ibáñez y Gusi Gener, 2004, 139, fig. 5, con bibliografía).

El cuenco carenado C-III-1 caracteriza los niveles del Bronce Final de la fachada mediterránea peninsular (Ruiz Zapatero, 2007). Los vemos en Andalucía Occidental y Oriental, allí con carenas altas o muy altas, como en Peñón de la Reina, Granada (Martínez Padilla y Botella, 1980, Fase IIIa); llegan hasta el Bajo Segura, con bordes exvasados y carenas algo más bajas o claramente bajas: Los Saladares (Arteaga y

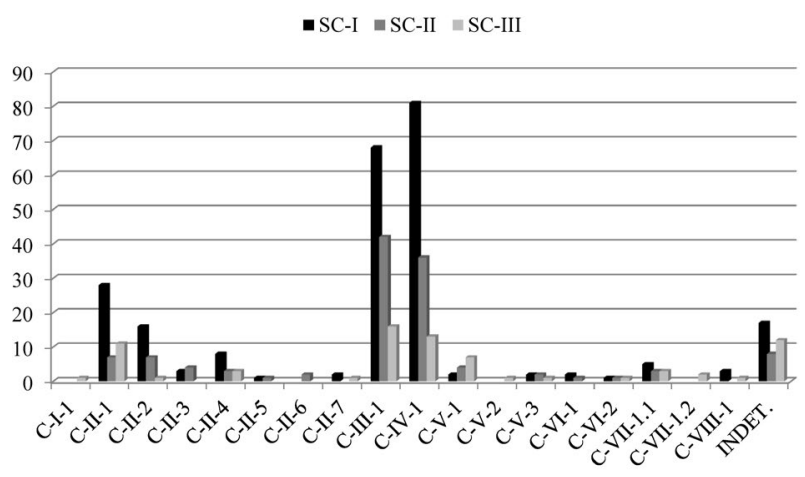

Figura 5: Formas de cerámicas Cuidadas. Fases I a III. 
Serna, 1975), La Fonteta (Rouillard, Gaidrellat y Sala, 2007, 219, figs. 176 y 187, Tipo 9); también en necrópolis del sureste, con carenas medias o bajas y borde exvasado (Lorrio, 2008, 230-232). En Peña Negra I, entre las múltiples variantes de estas copas, predominan las de carenas altas y hombro pronunciado, y sólo alguna podría parecerse a las nuestras (González Prats, 1985, 82, fig. 35); en todo caso estarían relacionadas con la forma B7B, y en Peña Negra II con las B2 y B9. En los 68 cuencos carenados de C-III-1 de La Solana predominan las carenas situadas en el tercio medio o superior de la pared, nunca cerca del borde, que es poco exvasado o casi vertical. Quizás en algunas copas carenadas del Bronce Tardío de la Illeta des Banyets encontraríamos precedentes de las nuestras (Gil Mascarell, 1981, 14, fig. 1, 1-3; Simón García, 1997, p.e. fig. 16).

El resto de los cuencos/copas tiene una representación escasa: el cuenco C-II-5, sin paralelos claros, y de conservación deficiente; el cuenco C-II-3, conocido en el área alicantina y tradición de los Grupos de Campos de Urnas (p.e. González Prats, 2002, 239, fig.182, forma T1C = B8 de Peña Negra I; Arteaga, 1982, 103104, Fase IA1); y el de perfil en «S» C-II-7, común desde Vinarragell hasta Saladares. Los cuencos C-II-4 pueden equipararse funcionalmente a los C-III-1, ya que sólo los hemos diferenciado por la ausencia de una carena clara.

Las cazuelas o fuentes carenadas C-IV-1, más numerosas que los cuencos carenados (81 ejs.), responden a tipos frecuentes en el Bronce Final desde el norte de nuestra geografía (p.e. Vinarragell, Mesado Oliver, 1974, fases I y II, figs. 79 1-3 y 57 2-3) hasta el Segura (p.e. Saladares, Arteaga, 1982, fases IA1 a IA3, figs. 17 y 23), con especial incidencia en lugares como Peña Negra (González Prats, 1985, p.e. figs. 12, 28, 29, 54, 57, etc); aunque en este área predominan las de bordes muy abiertos, de las que ahora sí encontramos algunos en La Solana. Entre las fuentes o cazuelas que no son carenadas, los pocos ejemplares de C-V-1 y $\mathrm{C}-\mathrm{V}-3$ responden también a prototipos frecuentes en el Bajo Segura y Vinalopó.

Las ollas son testimoniales. Destacamos la única C-VI-2, bitroncocónica y con decoración de acanalados gruesos horizontales, una forma característica de los Grupos de Campos de Urnas Antiguos y Recientes catalano-aragonenses (entre otros, Ruiz Zapatero, 1985,716 y $727-728$, figs. $2131-4$ y 2161,4 y 5 ; El Calvari: Castro, 1994, Forma I-1, Lám. II,1; Can Piteu - Can Roqueta: López Cachero, 2006, fig. 16; Cabezo de la Cruz: Picazo y Rodanés, 2009, 227, forma 4B, fig. 7,3 y 16, 3 y 6 ). Se documenta también, aunque de manera puntual, en toda el área alicantina.

Las grandes vasijas con tratamientos cuidados están débilmente representadas; destacamos la presencia de algunas con amplio cuello exvasado C-VII-1.1, similares a las que encontramos en necrópolis del sureste y que son raras en poblados; las vemos tanto en los Grupos de Campos de Urnas como en la Alta
Andalucía (Lorrio, 2008, 216-219, formas I-II). Las posibles vasijas cilíndricas responden a prototipos más antiguos, y continuarán como grandes recipientes de almacenaje hasta varios siglos después (p.e., en el Castellar de Librilla, Fase II, Ros Sala, 1989, 242-243).

Las decoraciones presentes sobre estos vasos cuidados son variadas, aunque se aplican en pocos de ellos. Las más numerosas son las incisas (20 ejs. $)^{6}$, sobre cuencos (C-II-1 y C-II-4) o copas carenadas (C-III-1) y sobre cazuelas (C-IV-1). El damero o los rombos rellenos de líneas paralelas (8 ejs.), combinados con otros motivos son casi exclusivos de esta fase. Aparecen, de norte a sur, como sobre el bello vaso polípodo de Almassora en Castelló (Clausell, 2002); en Los Villares de Caudete I y II (Mata, 1991, 159); en La Recueja (Albacete) al pie del Júcar, sobre cuencos C-II-3 y cazuelas C-IV-1 (Soria y Mata, 2002, 98, fig. 2) en el castillo de Requena (Martínez García et alii, 2001, 125, fig. 5-10); pero también en el área alicantina: Mola d'Agres (Peña Sánchez et alii, 1996, fig. 62, 11A), Peña Negra I (González Prats, 1983, 74, fig. 18; 1985, fig. 66, 69; láms. IX, XI, XIII) o Saladares (Arteaga, 1982, figs. 17 y 22). Lo mismo podemos decir del motivo de zig-zag (3 ejs.). También se documentan los triángulos rellenos de líneas paralelas (4 ejs.).

Encontramos la técnica del acanalado: acanalados anchos horizontales y paralelos (2 ejs.), relacionados con la forma C-VI-2 de tradición de Campos de Urnas como ya hemos visto; y acanalados finos (5 ejs.), con efecto de «bruñido sobre bruñido» ${ }^{7}$ que son propios de esta fase (cinco ejs. de un total de ocho) con diseños geométricos entre los que identificamos los triángulos rellenos de líneas paralelas (2 ejs.). En general, aparecen sobre cuencos simples o carenados y cazuelas carenadas pero también en vasos más grandes cerrados, de los que desgraciadamente no conservamos la forma.

Las impresiones de pequeños círculos, que festonean o rellenan otros motivos geométricos incisos, aparecen sobre cuencos simples o carenados y caracterizan también esta fase. Los encontramos similares en la fase V del Pic dels Corbs (Castelló) (Barrachina, 2012, figh. 59), en Peña Negra I (González Prats, 1983, 74, fig. 18; 1985, láms IX, XI y XIII) o en necrópolis del sureste (Lorrio, 2008, 242, fig. 130). No confundir con el motivo de «puntillado» frecuente en el Bronce Tardío valenciano (Pic dels Corbs, Mola d'Agres, Cabezo Redondo de Villena, Illeta des Banyets, etc.).

La decoración pintada se identifica en restos de pintura roja que ocuparía toda o gran parte de la pared

6. Las cerámicas incisas de La Solana están en estudio por Alejandra Macián.

7. «Incisiones muy finas, casi acanalados» (Ruiz Zapatero, 1985, 793-794); «acanalados poco profundos» o «acanaladuras incisas finas» en Mola d'Agres (Gil Mascarell, 1981, 27, figs. 2,4,5 y 7; Peña Sánchez et alii, 1996, 53 y 166, fig. 75); «acanalados finos» en Peña Negra I (González Prats, 1985, 81, láms. IX y XI), etc. 
del vaso, sin que se hayan detectado bandas $u$ otros motivos. Será más frecuente en el Hierro Antiguo. Esta técnica se utiliza desde el Neolítico (p.e. Andalucía), revitalizándose durante el Bronce Final, especialmente en Andalucía Oriental llegando en Cástulo hasta el s. VI a.C. Al norte del Ebro la encontramos en los Grupos de Campos de Urnas del Hierro (s. VII-VI) con origen en el bajo Aragón. Prácticamente ausente en Cataluña. En el País Valenciano, el yacimiento donde esta técnica es más frecuente es Los Villares de Caudete. Se aplica sobre vasos cuidados realizados a mano en las Fases I y II, ya en el Hierro Antiguo. La autora habla de un origen diverso, que puede venir desde la Cultura Campaniforme (desarrollo autóctono); de Andalucía, desde el s. IX; o del Valle del Ebro, entre los s. VII y VI a.C. (Mata, 1991, 159 a 163, figs. 86, 33; 87, 6, 8 y 14). En Los Villares aparece solo en rojo o combinada con amarillo y blanco, desarrollando motivos geométricos como damero, triángulos rellenos o no, grupos de líneas verticales u oblicuas, etc. Es frecuente también en Peña Negra (fases I y II), a menudo combinada con otros colores y formando igualmente motivos geométricos (González Prats, 1983, 121).

\section{Cerámicas Toscas (Fig. 6)}

Con un NMI de 147 piezas estudiadas, se reparten entre 13 formas distintas de las que casi el $70 \%$ son recipientes de almacenaje (T-VI-1, T-VII-1.1 y T-VII-1.2) y otros menos numerosos, seguramente de cocina (especialmente T-IV-1 y T-V-1).

Existe también un número relativamente amplio de recipientes de mesa $(11,56 \%)$ como cuencos simples o de casquete esférico (T-II-1) o de perfil en «S» (TII-5); de los restantes, es interesante resaltar la única copa con pie alto (T-II-2), y el gran recipiente carenado T-II-4, cuenco de grandes dimensiones y funcionalidad poco clara.

Entre las ollas, destacan las primeras de borde recto reentrante T-IV-1 (13 ejs.), que será tan numerosa en los niveles del Hierro Antiguo, donde la comentaremos; y el primer ejemplar de olla de borde vuelto T-IV-3, frecuente a partir de la fase Solana I, y que caracterizará a las fases del Bronce Final del Bajo Segura y el Vinalopó, así como de las comarcas centrales alicantinas.

Como es lógico, el repertorio más numeroso entre las cerámicas a mano toscas lo constituyen los recipientes de almacenaje $(55,78 \%$ del total), en especial diferentes vasos de cuellos rectos (T-VI-1) o exvasados (T-VII-1), de los que desgraciadamente no conservamos perfiles completos.

Fuera de estos repertorios, debemos mencionar el único ejemplar de soporte o «carrete» con refuerzo central T-IX-1, que nos remite de nuevo al Bronce Final de Andalucía. Son frecuentes en Peñón de la Reina (Martínez Padilla y Botella, 1980, 191, figs. 97, 147, 180 y 181, Fase IIIb) pero también en el Bajo Segura

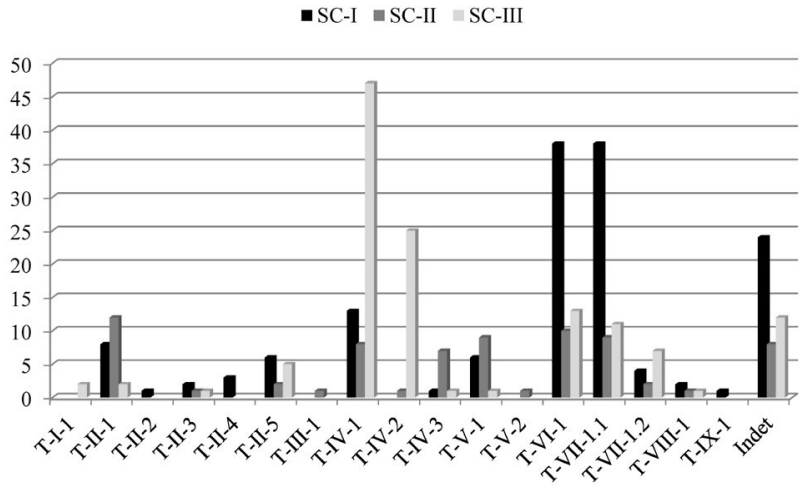

Figura 6: Formas de cerámicas Toscas. Fases I a III.

(p.e. Peña Negra I, González Prats, 1985, 81, figs. 69 y 73, forma $A B 3$ ), donde se seguirá registrando ya a torno por influencia fenicia.

En estas cerámicas encontramos apliques plásticos funcionales más que decorativos. Se trata de mamelones cónicos sencillos (10 ejs.), que continúan una antigua tradición que se remonta al Neolítico y sigue presente en el Bronce Tardío valenciano (Cabezo Redondo, La Illeta des Banyets, Pic dels Corbs, La Lloma de Betxí, L'Arbocer-Altet del Palau, etc.). En niveles del Bronce Final los documentamos en Andalucía Oriental: Cerro del Real (Pellicer y Schüle, 1966, p.e. fig. 13) o Peñón de la Reina (Martínez Padilla y Botella, 1980, fase IIIa, fig. 75, 6) por ejemplo. En tierras valencianas aparece en esa misma época en la necrópolis de Les Moreres sobre urnas T2 (nuestras T-V-1) y en la Peña Negra I (González Prats, 1985, fig. 56); en Casa de Secà, Elche, en el s. VII (Soriano, Jover y López, 2012, 85). Por las mismas fechas en el Puig d'Alcoi (Grau Mira y Segura Martí, 2013, 75), en el borde de cuencos simples T-II-1; en la Mola d'Agres, en la fase del Bronce Final /Hierro Antiguo (Peña Sánchez et alii, 1996, p.e. figs. 51, 52 y 53); o en los inicios de La Fonteta (725-700) (Rouillard, Gailledrat y Sala, 2007, fig. 175, 19; Ortiz, 2014, fig. 1).

Es propio de la fase Solana I un mamelón vertical alargado lobulado (2 ejs.). No es muy frecuente, pero lo encontramos en posición horizontal en el Peñón de la Reina, sobre ollas de perfil en «S», una de las formas más típicas del Bronce Final granadino (Martínez Padilla y Botella, 1980, fase IIIb, fig. 85). En la necrópolis de Les Moreres también, sobre un ejemplar de la olla de borde recto reentrante T-IV-1 (González Prats, 2002, 215-216, fig. 139).

\section{LAS CERÁmicas de la FASE Solana II}

\section{Cerámicas Cuidadas (Fig. 5)}

Comprende un NMI de 121 piezas estudiadas, con 13 formas distintas y porcentajes similares a los que vimos para Solana II. Así, los cuencos C-II-1, C-II-2, C-II-3 y C-II-4, y sobre todo los cuencos o copas carenadas 
C-III-1 y las cazuelas carenadas C-IV-1, constituyen el $81,81 \%$ (99 ejs.) del total de vasos de esta fase.

El repertorio de fuentes o cazuelas es poco frecuente fuera de la C-IV-1 (36 ejs.) antes mencionada. Incluimos aquí dos grandes cuencos carenados exclusivos de esta fase: C-II-6, con cuerpo troncocónico de inspiración en los grupos de transición del Bronce Final al Hierro de la Meseta (Ruiz Zapatero, 2007, Cerro de San Antonio, Madrid, fig. 3 n ${ }^{\circ}$ ) o de los Grupos de Campos de Urnas del medio y alto Ebro tardíos (Ruiz Zapatero, 1985, 745, fig. 222). También lo encontramos «versionado» en distintos yacimientos de Castellón (Orpesa la Vella, Barrachina y Gusi, 2004, 138, fig. $1 \mathrm{n}^{\mathrm{o}}$ 7117) y del Bajo Segura y Vinalopó (Peña Negra II, González Prats, 1982, 337, fig. 15; 2002, 301, fig. 210; Lorrio, 2008, 210-212 y 137,7). Las cazuelas con borde horizontal ondulado $\mathrm{C}-\mathrm{V}-1$ presentes en la fase anterior, serán más frecuentes en el Hierro Antiguo, como veremos.

Las ollas son testimoniales como en Solana I, destacando si acaso otra pieza acanalada perteneciente a una olla bitroncocónica C-VI-2. En cuanto a los grandes vasos profundos, muy escasos (3 ejs.) como en la fase anterior, responden a la forma C-VII-1.1 de cuello exvasado.

No son muchos los vasos decorados en esta fase, como ocurría en Solana I. Se repiten las mismas técnicas: acanalados, acanalados finos, incisión y pintura, con un menor número de ejemplares decorados. Señalamos únicamente la ausencia de motivos impresos (circulitos) que en la fase anterior festoneaban otros motivos incisos. En cuanto a éstos, son ahora más frecuentes los triángulos rellenos de líneas paralelas (5 ejs.), frente a la retícula o el damero (2 ejs.).

\section{Cerámicas Toscas (Fig. 6)}

Con un NMI de 72 piezas estudiadas pertenecientes a 13 formas distintas, la distribución en grupos formales es distinta a la que veíamos en Solana I. Así, aumenta el grupo de cerámica de mesa (cuencos/copas, cazuelas/fuentes) que representa el 20,81\%, frente al $13,60 \%$ de la fase anterior; también el número de ollas: $34,71 \%$ frente al $13,60 \%$, y por el contrario, bajan drásticamente los grandes contenedores: 31,91\% frente al 55,78\% de Solana I.

Entre los vasos de mesa, señalamos la única cazuela de carena baja del yacimiento, T-III-1, para la que no hemos encontrado paralelos exactos.

En cuanto a las ollas, destacamos el importante número relativo de las de borde vuelto T-IV-3, típicas de esta fase. Es una de las formas más frecuentes, junto a la olla de borde reentrante T-IV-1, de los niveles del Bronce Final del sureste peninsular y País Valenciano, perviviendo en el Hierro Antiguo. Ya en el área granadina, las ollas T-IV-3 las encontramos en Peñón de la Reina desde la Fase IIIa (s. VIII) hasta la IIIc (s. VII), donde es una de las formas más abundantes
(Martínez Padilla y Botella, 1980, 293-294, figs. 6970 , entre otras). También la encontramos en Librilla, forma III-F-6; en las fases iniciales de La Fonteta (Rouillard, Gailledrat y Sala, 2007, fig. 183 11; Ortiz, 2014, a3, 28-30, Fig. 3); en Los Saladares, en el nivel I-A3 (hasta VII-VI); en la Peña Negra, tanto en la Fase I (González Prats, 1985, figs. 30, 52, 55, 64 y 70; ídem 1983, Forma A6-B3) como en la Fase II (González Prats, 1982, fig. 10, 5959; 1985, figs. 12 y 50). Quizás también en Casa de Secà, Elche, en el s. VII (Soriano, Soler y López, 2012, 84-85). En la necrópolis de Les Moreres la encontramos como urna de la Fase I (González Prats, 2002, tipo T1C), aunque con muchas variantes. Aquí, el tratamiento exterior es cuidado (bruñido), como es habitual en las urnas cinerarias.

Siguiendo con el mundo de las necrópolis del sureste, podría ser la forma IV de Lorrio (2008, 204-205 y 219-220) o también la «olla de perfil en «S», forma Va (2008, 206-207 y 221-222, fig. 125). En las comarcas centrales valencianas se documenta en el Puig d'Alcoi, en el Hierro Antiguo mejor que en el Bronce Final I (Barrachina Ibáñez, 1987, 135, fig. 9) y en la Mola d'Agres, en la fase Bronce Final - Hierro Antiguo (Peña Sánchez et alii, 1996, 53, forma A-6/7). Al norte del Xúquer, al interior en Los Villares, tipo 1 (orza) o 2 (olla), de gran tamaño. En un ejemplar de la Fase II (más tardía), presenta un asa de herradura; más frecuentes son los cordones aplicados en el cuello y digitaciones o incisiones en el borde (Mata, 1991, 143, fig. 77). En el Camp del Túria, en el Tossal de Sant Miquel, bajo departamentos ibéricos, fase Bronce Final - Hierro Antiguo; también en la Cova del Cavall, como urna cineraria, en este caso con acabado cuidado, espatulado (Bonet Rosado, 1995, 376 y 116, fig. 3). Al norte del Palancia, en el Torrelló de Boverot (Almassora) y en Vinarragell.

Siguen presentes las ollas de borde reentrante T-IV1, y la primera T-IV-2 de borde estrangulado, característica de fases posteriores al Bronce Final.

Son numerosas las vasijas de borde vertical recto, T-V-1, abundantes en el Bajo Segura y el Vinalopó: forma IV de Lorrio (2008, 204-205 y 219-220), en las fases iniciales de La Fonteta (Rouillard, Gailledrat y Sala, 2007, fig. 183,8; Ortiz, 2014, A7D, 39-40, fig. 9d) o en Los Saladares, fase IA3. En la necrópolis de Les Moreres (con tratamiento bruñido), es una de las variantes de la forma T1C (González Prats, 2002, 239, fig. 182); también en la fase I de Peña Negra, forma 6 A2b (González Prats, 1979, fig. 64, 109; 1983; 1985, figs. 28, 52, 55, 70 y otras); en Caramoro, fase de Bronce Final II. s. IX-VIII (González Prats y Ruiz Segura, 1992, figs. 3 y 4); lo mismo observamos en Casa de Secà, Elche, ya en el s. VII (Soriano, Jover y López, 2012, 84-85, fig. 10.1). Por último, llega al interior alicantino en la Mola d'Agres, fase reciente (Peña Sánchez et alii, 1996, 53, forma A-7).

Es única la vasija profunda de borde ligeramente exvasado $\mathrm{T}-\mathrm{V}-2$, caracterizada por presentar un doble tratamiento: cuidado en el borde y rugoso en el cuerpo 
del vaso. Esta combinación es propia del Bronce Final Tartésico, apareciendo por vez primera en Colina de los Quemados (s. IX-VIII), generalizándose en el momento que precede a las importaciones fenicias (Aubet, 1975, 134-136). En Huelva la encontramos en el Cabezo de San Pedro o San Bartolomé de Almonte; y en Sevilla, en el Carambolo Alto y en Valencina de la Concepción, en niveles del Bronce Final. Es común en los siglos VII-VI: Carambolo Bajo, Carmona, Cerro Salomón, necrópolis de Cruz del Negro, o la misma Setefilla. La forma más semejante a nuestro vaso se corresponde con el tipo G.I.a.1 de San Bartolomé de Almonte, donde las ollas suelen presentar además el doble tratamiento en cuello y cuerpo del vaso (Ruiz Mata y Fernández Jurado, 1986, 175-176, cuadro 35, 191 y 213 , láms. XI, XII y XIII). En Cataluña se documenta igualmente en los Grupos de Campos de Urnas Recientes o Bronce Final III (Pons y Maya, 1988, $551)$, en hábitats y no en necrópolis. En un momento más avanzado, este tratamiento aparece en los Campos de Urnas del Hierro (s. VI-V a.C.) del Grupo Costero Catalán (Ruiz Zapatero, 1985, 739-740, fig. 220, nº11) sobre vasos de perfil en «S» con base plana. Fue publicado por vez primera por S. Vilaseca $(1969,179-187)$, en un importante lote de recipientes cerrados de la Cova de la Font Major con borde ligeramente exvasado y decoración de cordones, incisiones o impresiones que separan la zona con tratamiento cuidado (cuello, borde) de la de tratamiento rugoso (cuerpo del vaso). Estarían unos y otros dentro de una misma tradición languedociense, en contextos del s. VI a.C.

Ya en el sureste se documentan en el Cerro de la Encina de Monachil (Arribas et alii, 1974, estr. III, fig. $60,153)$ y en Los Saladares, del Bronce Final Pleno y Reciente (Arteaga, 1982, Fase IA2, 105-106, fig. $\left.28, n^{\circ} 27\right)$, algunos con el doble tratamiento de la superficie. En Peña Negra encontramos esta forma en la fase I, aunque no se especifica el tratamiento (González Prats, 1979, figs. 63 y 64, 102; 1985, fig. 30, 849, quizás la forma A1). En la necrópolis de Les Moreres correspondería a la forma 6 de Peña Negra I, como la anterior. El vaso de La Solana podría corresponder por la forma a la tradición del Bronce Final andaluz, más que a la del Bronce Final catalán.

Las grandes vasijas de almacenaje repiten formas de Solana I, aunque en porcentajes menores, como hemos comentado al principio.

Los elementos aplicados, de carácter funcional y muy escasos, se limitan a un pequeño mamelón cónico y un cordón fino con digitaciones, motivos que ya veíamos en Solana I.

\section{LAS CERÁMICAS DE LA FASE SOLANA III}

\section{Cerámicas Cuidadas (Fig. 5)}

Se registra un NMI de 74 piezas pertenecientes a 14 formas distintas, con porcentajes similares a los que vimos en fases anteriores, aunque algo menores debido a la mayor presencia de fragmentos no atribuibles a forma determinada (14 ejs., 14,45\%). Entre las copas/ cuencos las más numerosas son las carenadas C-III-1 (16 ejs.), seguidas por los cuencos simples C-II-1 (11 ejs.), que encontramos también en La Fonteta (Ortiz, 2014, B4A, 49, fig. 13). Destaca el carácter residual de C-II-2, y la aparición del plato C-I-1, con tratamiento grafitado, similar a la forma B1 de Peña Negra II.

Las fuentes o cazuelas más comunes son como en fases anteriores las carenadas ( 13 ejs.), aunque destacamos la frecuencia relativa de las fuentes de borde aplanado C-V-1, que reúne la mayor cantidad de éstas entre todas las fases (7 ejs.). Las encontramos en la Fase I de Peña Negra, aproximadamente su forma B5. Más al sur, en Saladares, en la Fase IA1 (850-775 aprox) pero también en la IA3, ya con materiales fenicios, fechada a partir del 725 a.C. En Los Villares de Caudete encontramos unos «cuencos con lengüetas que sobresalen del labio» (Mata, 1991, 153, figs. 84, 87 y 88 ), que podrían ser similares a los nuestros (Fases I y II).

Es también el primer momento de la fuente de borde exvasado $\mathrm{C}-\mathrm{V}-2$, que luego encontramos en el Ibérico Antiguo. No es una forma muy frecuente, pero cazuelas parecidas se documentan en el Bronce Final desde Vinarragell (Mesado Oliver, 1974, fig. 79, 5-6, nivel O), a Peña Negra I (González Prats, 1985, fig. 58, 1747), pasando por la última fase de La Mola d’Agres (Peña Sánchez et alii, 1996, 53, forma B-4).

Como es habitual, el conjunto de copas/cuencos y fuentes/cazuelas, recipientes de mesa, constituyen un alto porcentaje entre las cerámicas cuidadas $(73,31 \%)$, menor sin embargo que en fases precedentes. Las grandes vasijas quedan reducidas a un modesto $6,75 \%$, que es sin embargo mayor que en el Bronce Final. Debemos mencionar la presencia de un fragmento con decoración de acanalados horizontales, perteneciente a una olla bitroncocónica C-VI-2, como las registradas en fases anteriores.

También dos vasos cerrados de los que sólo conocemos el cuello y el arranque del cuerpo, posiblemente globular, C-VII-1.2, similar al llamado «Vaso à chardon» de época orientalizante andaluza. Si se tratase de una forma como la que comentamos, encontramos paralelos en las urnas cinerarias de la necrópolis de Setefilla (s. VII) donde son mayoritarias, con un original tratamiento de la superficie: cuello bruñido y cuerpo ovoide rugoso (Aubet Semler, 1975, 74-77). También las encontramos con la misma cronología en Andalucía Occidental: San Bartolomé de Almonte (Huelva) o necrópolis de La Joya (Huelva) (Ruiz Mata y Fernández Jurado, 1986, 193-195).

En nuestro entorno, en Los Villares encontramos fragmentos de borde que podrían asimilarse a la misma forma; Mata propone que podría tener vinculaciones con el mundo hallstáttico, en cuanto que una de ellas presenta un tratamiento grafitado; también reconoce que pudiese tratarse de una imitación de los vasos «à 
chardon». (Mata, 1991, 157, figs. 83,1 y 88, 10). Por último, en Peña Negra II (González Prats, 1979, fig. 34,9 , tosca; 1983) podría corresponderse con la forma B10b. También aparece a torno, en la misma Fase II (González Prats, 1979, fig. 82, 11-12, gris; 1982, 337, fig. 15). En la necrópolis del Collado y Pinar de Santa Ana (Jumilla) la encontramos a torno, acompañando a cerámicas fenicias a finales del $\mathrm{s}$. VIII (Hernández Carrión y Gil González, 2004, Sep. 5, fig. 6c).

De las decoraciones aplicadas a la superficie de los vasos, son testimoniales los acanalados finos y gruesos. Las cerámicas con decoración incisa son más frecuentes que en fases anteriores (12 ejs.), predominando el motivo de triángulos rellenos de líneas paralelas ( 8 ejs.), que también aparece en la técnica de acanalados finos en esta misma fase. Es este un motivo común desde el Bronce Tardío y Final de la Meseta (Abarquero, 2005, 315); igualmente lo encontramos en los Campos de Urnas Antiguos con acanalados en Cataluña y Valle del Ebro, y ya con incisiones a partir de Campos de Urnas Recientes (Ruiz Zapatero, 1985, 733-734, fig. 218, 15 a 18). En realidad, como dice Abarquero, es uno de los motivos más frecuentes de todos los horizontes culturales que conviven en la península Ibérica entre finales del Bronce Final y los inicios de la Edad del Hierro.

En tierras valencianas se documentan en el Bronce Final y Hierro Antiguo desde Castellón: Vinarragell (Fase III, con cerámicas a torno fenicias), Puntales del Pollino (Altura) (Oliver, 1993, 319-320, fig. 4, 2-4; Mesado Oliver, 1974, fig. 72, 1) entre otros. En el Pic dels Corbs (Barrachina Ibáñez, 2012, fig. 59) encontramos algunos en la Fase V (1000/950 - 700/650). En Llìria, en la Cova del Cavall (Bonet Rosado, 1995, 122-124, lám. II). En Los Villares de Caudete es más abundante en la Fase I, pero presente también en la fase II (Mata, 1991, 159, fig. 86). Por último, en el castillo de Requena aparecen sobre cuencos tipo C-II-3 y C-II-7 (Martínez García et alii, 2001, 125, fig, 5, 1-10). En las comarcas centrales alicantinas, los encontramos en La Mola d'Agres, en diferentes composiciones y combinados con otros invertidos (Peña Sánchez et alii, 1996, fig. 61, 8; fig. 63, 13B).

En el sur de Alicante, son abundantísimos en la Peña Negra I (González Prats, 1983, 74, fig. 18; 1985, figs. 54, 66, 69, 71, láms. X, XI, XIII, en algún caso con pasta blanca; 1990, 74), a menudo combinados con otros motivos, y tanto por el exterior como por el interior de copas o vasos abiertos; también en El Tabaià (Belmonte, 2004, 340-342), en un momento muy temprano, a caballo del Bronce Tardío y Final. En Los Saladares, igualmente combinados con otros motivos, en bordes o cuellos de vasos abiertos, desde la fase IA1 del Bronce Final Pleno, hasta el Hierro Antiguo, fase IA3 (Arteaga, 1982, figs. 17 y 22).

En diversas necrópolis del sureste peninsular aparecen en cuellos o bordes de urnas cinerarias, así como en el borde de algunas cazuelas (Lorrio, 2008, 214 y 238, fig. 128); y en La Recueja, pueblo albaceteño lindante con Valencia, las encontramos igualmente sobre cuencos C-II-3 y cazuelas C-IV-1 (Soria y Mata, 2003, 98, fig. 2).

La decoración de pintura roja, sin motivos identificados, está presente de manera más notoria que en el Bronce Final (7 ejs.). Ya vimos, al hablar de esta técnica decorativa en la Fase Solana I, como es la más frecuente en Los Villares de Caudete, especialmente en fases del Hierro Antiguo.

Destaca por último la aparición de la técnica del grafitado, aplicado tanto por el exterior como por el interior de vasos abiertos. De tradición exógena, parece que su origen está en el sur de Francia, de donde pasaría al País Vasco hacia la primera mitad del s. VIII y de allí se extendería por el interior de la península. Es frecuente en la Meseta, y su punto más al sur es Cástulo (Jaén), donde se fecha entre finales del s. VIII y el s. VII. La misma fecha admite C. Mata para Los Villares de Caudete, uno de los pocos yacimientos valencianos donde hay constancia de esta técnica decorativa, tanto en la Fase I como en la II (1991, 163-164, fig. 88). También los encontramos en el Castillo de Requena, en una fase de Hierro Antiguo (Martínez García et alii, 2001, 125, fig, 5, 11). Precisamente el platillo C-I-1 porta dicho tratamiento, y es posible que estemos ante un vaso importado.

\section{Cerámicas Toscas (Fig. 6)}

Este bloque comprende un NMI de 128 piezas. Se reduce claramente el porcentaje de cerámicas de mesa: un $7,81 \%$ del total; seguramente tiene mucho que ver la llegada de cuencos y platos a torno fenicios, que hemos mencionado más arriba. Destacamos la aparición de la pátera de borde reentrante T-I-1, de la que encontraremos otro ejemplar en el Ibérico Antiguo, y que formalmente podría relacionarse con el repertorio fenicio, aunque no faltan paralelos en cerámicas a mano desde el Bronce Tardío del País Valenciano: Cabezo Redondo, Illeta des Banyets, El Negret, El Tabaià y otros, pero a menudo con tratamiento cuidado. En el Tabaià se la identifica con la fuente «tipo Monachil», característica de Andalucía Oriental (Belmonte, 2004, 338, fig. 4, 6). Algo más reciente, en El Puig (Alcoi), más del siglo VII que del IX (Barrachina Ibáñez, 1987, $134,6)$, con una cronología concordante con las piezas de La Solana. Por último, también en el Hierro Antiguo del Guadalentín, en el Castellar de Librilla, con cerámicas a torno (Ros Sala, 1989, 229-230, forma II-C.2).

El número de ollas T-IV-1 y T-IV-2 es ahora el más alto $(57,81 \%$ del total), certificando la importancia de estos recipientes que abundan en niveles del Hierro Antiguo entre el Segura y el Xúquer. La T-IV-1 es la misma que se documenta en el área granadina y Murcia bajo el nombre de «orzas» (Martínez Padilla y Botella, 1980, 293-294, Fase IIIa; Ros Sala, 1989, 242-243, forma II-F-4). Ya en el Bajo Segura podemos 
citar su presencia en Saladares, en las primeras fases de La Fonteta (Rouillard, Gailledrat y Sala, 2007, fig. 175,6; fig. 183, 1 a 3; fig. 184, 5 a 7; Ortiz, 2014, A1/ A2, 24-27, figs. 1 y 2) y es una de las más frecuentes en Peña Negra, tanto en la Fase I como en la Fase II, correspondiéndose con las formas A2 y A3 (González Prats, 1982, fig. 10; 1985, figs. 12, 28, 52, 55, 58, entre otras). Lo mismo ocurre con la necrópolis de Les Moreres, donde es la urna de incineración más frecuente en la fase II o del Hierro Antiguo, aunque ya aparece alguna en Moreres I (González Prats, 2002, 239-242, Tipo T-2). En el Vinalopó en Casa de Secà, Elche, en el s. VII (Soriano, Jover y López, 2012, 84-85). En las comarcas interiores de Alicante, en la Mola d'Agres (s. IX-VII a.C.), bajo la forma A-7 (Peña Sánchez et alii, 1996, 53), así como en el Puig d'Alcoi, en el Hierro Antiguo (Barrachina Ibáñez, 1987, fig. 8, ollas tipo 4; Grau Mira y Segura Martí, 2013, tipo C, 77-79). Por último, en la comarca de Requena Utiel se documenta en Los Villares, aunque su autora los identifica más con cuencos que con ollas (Mata, 1991, Tipo 3, subtipo $1 ; 147$, figs. 78,80 y otras).

La de borde estrangulado T-IV-2, es frecuente en las mismas zonas: Castellar de Librilla, nivel II; en Saladares 1A y 1B (Arteaga y Serna, 1975); en La Fonteta (Rouillard, Gailledrat y Sala, 2007, Fase II, fig. 183, 14; Ortiz, 2014, A6, 36-38, fi. 8); en la necrópolis de Les Moreres, Fase I (González Prats, 2002, 239, fig. 182, T1C); en Peña Negra I, forma A6, perdurando en la Fase II del Hierro Antiguo. Lo mismo observamos en Casa de Secà, Elche, en el s. VII (Soriano, Jover y López, 2012, 84-85). Es la olla más frecuente en los niveles de Hierro Antiguo del Puig d'Alcoi (Grau Mira y Segura Martí, 2013, tipo B, 77-79). En Mola d'Agres, sería la forma 7 (Peña Sánchez et alii, 1996, 90-93, figs. 50-56). Al norte del Xúquer, la documentamos en Vinarragell.

Los grandes vasos de almacenaje siguen presentes $(25 \%)$, si bien nunca con la importancia que tuvieron en el Bronce Final.

En cuanto a los elementos aplicados, funcionales o decorativos, son frecuentes los mamelones cónicos pequeños ( 7 ejs.). Aunque lo verdaderamente característico de esta fase es la aparición de los mamelones verticales alargados simples (9 ejs.) o con una depresión central (6 ejs.), situados cerca del borde de las ollas T-IV-1 y T-IV-2. En la misma posición y sobre las mismas ollas u «orzas» los vemos en el área granadina (Martínez Padilla y Botella, 1980, 293-295), en el Bajo Segura (Castellar de Librilla, Ros Sala, 1989, 242-243; Saladares, Arteaga, 1982, 106; en La Fonteta (Rouillard, Gailledrat y Sala, 2007, fig. 175, 18; 183, 16; 185, 4, Fases I y II; Ortiz, 2014, 24, figs. 1 y 2a); en Peña Negra y les Moreres (González Prats, 1982, fig. $10 ; 1985$, p.e. figs. 12 y 56, Fases I y II; 2002, T-2, 239-242 fase orientalizante) y en el Vinalopó (Casa de Secà, Soriano, Jover y López, 2012, 85). Así mismo es el tipo de mamelón más frecuente en el Puig d'Alcoi (Grau Mira y Segura Martí, 2013, 75).
También por vez primera encontramos mamelones circulares aplastados con depresión central y pequeñas «pastillas» aplicadas de las que conocemos paralelos en el Bronce Final de la Illeta des Banyets (Simón García, 1997, fig. 25, 8) o en el Pic dels Corbs (Barrachina Ibáñez, 2012, Fase III, 73) y más recientes, en La Fonteta (Rouillard, Gailledrat y Sala, 2007 Fase II, 700-650, fig. 186, 32; Ortiz, 2014, 26, fig. 2a).

Destacamos por último un asa en forma de herradura o estribo de tradición tartésica $u$ orientalizante andaluza (Cerro Salomón, Blanco, Luzón y Ruiz Mata, 1970, nº55, 56, 57, 102, 137, etc.; Cabezo de San Pedro, San Bartolomé de Almonte, Tejada la Vieja, Cerro Macareno, Niebla, etc, Ruiz Mata et alii, 1986). La seguimos encontrando en el área granadina (Peñón de la Reina, Martínez Padilla y Botella, 1980, fig. 758 a 10; fig. 111, 6) y Bajo Segura (Castellar de Librilla, Ros Sala, 1989, 242-243; Saladares Fases IA2 y IA3, Arteaga y Serna 1975, lám. IX, 65 y III, 19; 1980, 107; La Fonteta, Ortiz, 2014, 27, fig. 2a) sobre ollas u «orzas» T-IV-1; e incluso en Los Villares de Caudete, sobre una olla de nuestro tipo T-IV-3 (Mata, 1991, 143, fig. 77, 2).

\section{APUNTES SOBRE LA FUNCIONALIDAD DE LAS CERÁMICAS A MANO DE LA SOLANA DEL CASTELL}

No hemos documentado hasta el momento la asociación de vasos y restos carpológicos o antracológicos que nos permitan confirmar su uso, especialmente en lo que se refiere a los vasos de almacenaje. No obstante vamos a proponer en este apartado algunos aspectos de funcionalidad ligados a la forma de los mismos.

\section{Cerámicas Cuidadas (Fig. 7)}

Estamos ante una vajilla con tratamientos cuidados (bruñido generalmente), bien cocida y de grano medio o fino, que comprende formas destinadas al servicio de

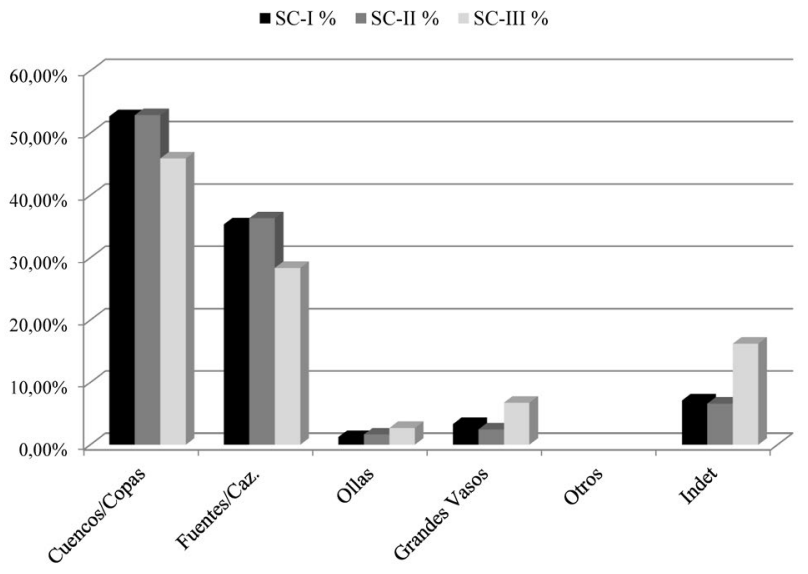

Figura 7: Funcionalidad de cerámicas Cuidadas. 


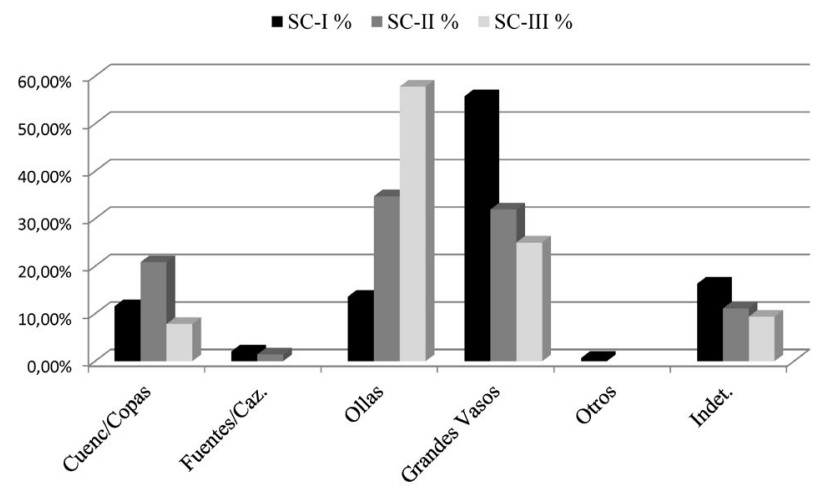

Figura 8: Funcionalidad de cerámicas Toscas.

mesa. Así, aunque la polivalencia de este tipo de vasos debía ser frecuente, nos atrevemos a asignarles una posible funcionalidad habitual: cuencos o copas para beber de uso individual, por su pequeño tamaño (algunos cuencos C-II-1, C-II-2, C-II-4 y especialmente copas/cuenco C-III-1); recipientes para comer (p.e. algunos C-II-1, las cazuelas o fuentes C-IV-1) y otros para servir o presentar alimentos (las mismas cazuelas C-IV-1, C-V-1, C-V-2 y C-V-3). Entre las grandes vasijas profundas, C-VII-1.1, es adecuada para contener y conservar líquidos (agua), mientras que C-VIII-1, de grandes paredes verticales, podría tener un uso polivalente para agua o para cereales y leguminosas.

En la fase Solana II aumentan los tipos de recipientes para comer de forma colectiva (se añaden ahora C-II-5, C-II-6), manteniéndose los distintos grupos funcionales en proporciones muy similares.

Para el Hierro Antiguo (Solana III), debemos tener en cuenta la existencia de importaciones fenicias occidentales, especialmente ánforas de transporte (NMI: 21 ejs.) pero también cuencos y platos de barniz rojo o grises (NMI: 7 ejs.), una jarra de boca trilobulada y recipientes cerrados distintos a las ánforas, entre las que se encuentran algunos pythoi y otros fragmentos de forma no identificada (NMI: 10 ejs.). Completarían los grupos funcionales de las cerámicas a mano, que como vemos en la fig. 11, tienen porcentajes inferiores a los del Bronce Final.

\section{Cerámicas toscas (Fig. 8)}

En Solana I, es lógico el poco peso que proporcionalmente tiene el grupo de la vajilla de mesa, debido al papel jugado por los vasos de acabado cuidado. La funcionalidad de las escasas ollas y de las numerosas vasijas profundas de cuello recto o exvasado sería fundamentalmente el almacenaje de productos alimenticios sólidos o líquidos, como conocemos por otros yacimientos.

En Solana II hay una mayor presencia de vajilla de mesa que en la fase anterior, aunque siempre muy por debajo de los porcentajes de cerámicas cuidadas de las mismas formas. La mayor cantidad de ollas parece indicar una sustitución progresiva de los grandes contenedores por otros de menor tamaño, con bocas más pequeñas y muchos de ellos preparados para recibir tapaderas, más adaptados a la cocción de alimentos, aunque no hemos encontrado trazas claras de este uso entre las piezas estudiadas.

En Solana III se acentúa la tendencia a la sustitución de grandes recipientes por ollas. Es complicado hacer hipótesis sobre la funcionalidad de las mismas, pero es evidente que nos hablan de un cambio en las costumbres culinarias de los habitantes de nuestra área geográfica, seguramente con una mayor atención a las cocciones de alimentos y a un almacenaje variado y más selectivo, destinando ollas y grandes envases a guardar y almacenar distintos tipos de productos; deberemos sin embargo confirmarlo con hallazgos concretos.

\section{LAS CERÁMICAS A MANO DE LA SOLANA DEL CASTELL EN EL MARCO DEL TERRITO- RIO ENTRE EL XÚQUER Y EL SEGURA (Fig. 9)}

Como decíamos en la introducción, la ubicación de La Solana del Castell convierte al yacimiento en un lugar de control de los flujos humanos y materiales que circulan en sentido NW-SE (Valle del Vinalopó y Meseta hacia llanuras aluviales del Xúquer-Túria). El inicio del asentamiento, a partir de los siglos X-IX a.C., parece coincidir con el comienzo de contactos ultramarinos que tienen lugar en las costas valencianas, antes aún del establecimiento de gentes fenicias occidentales en ellas (Vives Ferrándiz, 2006; Rouillard, Gailledrat y Sala, 2007; González Prats, 2011 y 2014). En este sentido, es importante destacar la comunicación de La Solana con la desembocadura del Xúquer y con la línea de costa, donde el yacimiento de l'Alter de la Vintihuitena, lamentablemente sin publicar, reúne cerámicas a mano del Bronce Final y las primeras importaciones fenicias a torno que llegan por mar (Mata y Bonet, 2001, 178). Está apenas a $30 \mathrm{~km}$ de distancia (un día de camino) siguiendo primero el río Albaida y luego la margen derecha del Xúquer hasta l'Alter, donde un vado histórico por donde luego cruzó la Via Augusta, facilita el paso. Otros itinerarios comunican La Solana con el mar, a través de barrancos como el de Barxeta o el paso de Vernissa, hacia Tabernes de la Valldigna y Gandía. Ambos itinerarios no superan los $35 \mathrm{~km}$, sin grandes desniveles.

La comunicación con el Camp del Túria y el Palància se debió realizar por el itinerario histórico que luego fosilizó la Via Augusta. Desde el vado de L'Alter, bordeaba la laguna de La Albufera y conducía a los llanos aluviales del Túria donde se ubica por ejemplo Tossal de Sant Miquel, y de allí al Palància, en cuya margen izquierda está el Pic dels Corbs. Hemos visto como a través de las cerámicas encontramos rasgos comunes entre ambos territorios, si bien no tan estrechos 


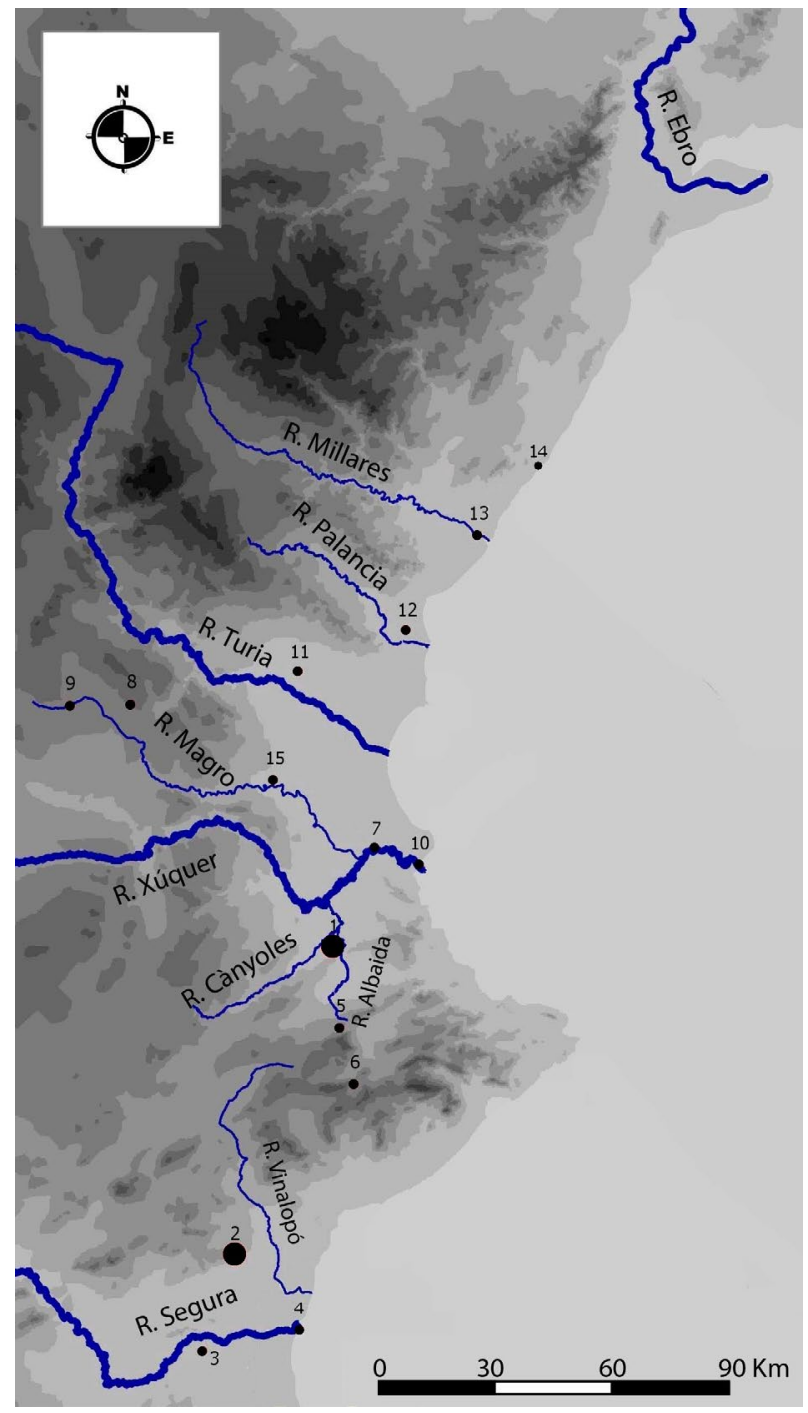

Figura 9: Principales yacimientos citados en el texto. 1: La Solana. 2: Peña Negra. 3: Saladares. 4: La Fonteta. 5: La Mola d'Agres. 6: El Puig d'Alcoi. 7: L'Alter de la Vintihuitena. 8: Castillo de Requena. 9: Los Villares de Caudete. 10: Cullera. 11: Tossal de Sant Miquel de Llíria. 12: Pic dels Corbs. 13: Vinarragell. 14: Orpesa la Vella. 15: La Carència.

como con el Valle del Vinalopó. Más al norte, la comunicación era sencilla por los llanos costeros castellonenses, con ramblas y ríos de fácil vadeo como el Millars en cuyo tramo final se encuentran El Torrelló d'Almassora y Vinarragell; el Riu Sec o el Sènia, antes de llegar al Ebro. No queremos decir que hubiese una constante comunicación con estas tierras más lejanas, pero sí que el paso no tiene obstáculos naturales y pudieron fluir por este camino intercambios e ideas. La existencia de perlas de ámbar como la nuestra en el Pic dels Corbs (Barrachina Ibáñez, 2012, 102, foto 34) está seguramente en relación con yacimientos de ámbar en el interior de la Sierra Calderona, en proceso de estudio. Mirando un poco más lejos, por esta ruta septentrional pudo llegar la tradición decorativa de acanalados originaria de los Grupos de Campos de Urnas, y formas cerámicas como el vaso bitroncocónico
C-VI-2, que seguimos luego débilmente hasta el Valle del Vinalopó.

La comunicación con la Meseta tiene otro itinerario por la comarca de Requena-Utiel: allí se encuentran los asentamientos del Castillo de Requena y Los Villares de Caudete. Se alcanza esta comarca desde el Valle del Xúquer siguiendo el valle del Magro (Quixal, 2012), río que precisamente desemboca en el Xúquer en las proximidades de l'Alter de la Vintihuitena. Hacia la mitad del camino se encuentra La Carència de Torís, yacimiento ibérico (¿Kili?) pero que ha proporcionado también cerámicas a mano incisas del Bronce Final. De esta zona, en contacto con la Meseta (Cuenca), pudo llegar al Bajo Xúquer en el Hierro Antiguo la técnica del grafitado. La frecuencia de decoraciones incisas en cerámicas a mano del Castillo de Requena, Los Villares y otros del Alto Xúquer (Martínez, Cháfer y Espí, 2001; Mata, 1991; Soria y Mata, 2002) nos hablan de una de las posibles vías de llegada desde la Meseta a La Solana de esta tradición decorativa en el Bronce Final. Hemos de señalar su ausencia casi total en los niveles del Bronce Final de Andalucía Oriental y Sureste, y su presencia abundante en el Vinalopó y Bajo Segura: allí, (p.e. Peña Negra) o bien surgió de una evolución local a partir de tradiciones campaniformes existentes en la zona (aunque con un vacío cronológico de casi un millar de años), o más seguramente llegó con gentes que «bajaron» del área manchega al Valle del Vinalopó, siguiendo una ruta bien conocida de antiguo, que las gentes de la Meseta podrían frecuentar con sus ganados hacia la costa (Hernández, 2005, 24-25).

Precisamente, la comunicación con el Valle del Vinalopó y la Meseta (zona de Albacete/Cuenca) a través del Valle del Canyoles, ha sido propuesta por nosotros para el mundo ibérico (Pérez Ballester y Borredá, 1998). En el Bronce Final y el Hierro Antiguo de La Solana, más del $80 \%$ de las formas cerámicas tienen paralelos claros en yacimientos del Bajo Segura y Vinalopó, especialmente con la Peña Negra (Bronce Final y Hierro Antiguo) y La Fonteta (Hierro Antiguo). Los cuencos C-II-1, C-II-3, C-II-4, C-II-1; las fuentes o cazuelas $\mathrm{C}-\mathrm{V}-1$ y $\mathrm{C}-\mathrm{V}-3$, las ollas T-IV-1 y T-IV-2, la vasija T-V-1, y las numerosas decoraciones incisas, son comunes al sur del Xúquer. En cambio, los cuencos y cazuelas carenados C-III-1 y C-IV-1 se extienden por todo el territorio valenciano, como característicos del Bronce Final en el Levante y Sureste peninsular.

A través del Bajo Segura y Vinalopó, podemos detectar lo que hay en común con las tradiciones cerámicas del Sureste y Andalucía Oriental (Granada). Fundamentalmente es el uso de las ollas de borde reentrante T-IV-1 (allí llamadas «orzas») y las de borde estrangulado T-IV-3. Más ocasionalmente, la aplicación de mamelones verticales alargados, o de asas en forma de herradura, y puntualmente otras formas más raras como podría ser el vaso profundo con doble tratamiento $\mathrm{T}-\mathrm{V}-2$, el soporte o carrete T-IX-1, con ecos 
en la Peña Negra, y la forma C-VII-1.2, que recuerda tanto al vaso «à chardon» del área tartésica.

Curiosamente, a pesar de su relativa proximidad, son marginales para La Solana los yacimientos situados en el entorno de Alcoi, como el Puig o la Mola d'Agres; quizás por el aislamiento que supone el territorio montañoso que encierra la comarca, y el difícil paso del Port d'Albaida. En época ibérica lo hemos considerado el límite más occidental del territorio de Saitabi (Pérez Ballester y Borredá, 2008). El Puig, con niveles del Hierro Antiguo, presenta entre las ollas una mayor presencia de las de borde exvasado T-IV-2 sobre las «orzas» u ollas de borde reentrante T-IV-1, tan numerosas en La Solana y en el Bajo Segura / Vinalopó, y tiene fuertes relaciones con yacimientos costeros alicantinos como Illeta des Banyets. La Mola d'Agres, con niveles más potentes del Bronce Tardío frente a los del Bronce Final, recoge en su fase del Bronce Final - Hierro formas que estando presentes en La Solana, no lo son con la frecuencia de ésta. No obstante, el hallazgo en Solana I de parte de un brazalete de marfil, similar a los numerosos hallados en la Mola d'Agres, nos hace pensar que las relaciones de intercambio con esa comarca existirían con total seguridad.

\section{UNA RECAPITULACIÓN}

Las cerámicas a mano de La Solana del Castell de Xàtiva nos ofrecen un panorama que parece confirmar por un lado el territorio común que debió existir en el Bronce Final entre el Xúquer y el Vinalopó/Bajo Segura, como ocurrirá luego en época ibérica (la Contestania), con dos grandes asentamientos principales: la Solana y Peña Negra, accesibles por los Valles del Vinalopó y el Canyoles. Son palpables los contactos puntuales de La Solana con la Mola d'Agres (marfil), seguramente con el valle del Palància (ámbar?) y con el mundo meseteño por intermedio de la comarca Requena-Utiel (técnicas decorativas del grafitado y de la incisión). De la zona del Ebro es indudable que debió llegar la técnica de los acanalados, inexistentes hasta entonces en nuestra región.

Estos últimos datos nos hacen reflexionar con el sentido de «frontera» o «límite» que tradicionalmente se ha aplicado a la línea del Xúquer. Es seguramente un límite, pero fácilmente franqueable, vadeable, navegable incluso, que facilitó la permeabilidad de personas y bienes, que a nosotros nos queda fosilizada en la limitada presencia de la cerámica y algún que otro objeto suntuario.

A partir de finales del siglo VIII y especialmente durante todo el siglo VII, sin negar la posibilidad de contactos anteriores, La Solana entra en relación con los comerciantes ultramarinos. Mejor dicho: esos comerciantes entran en contacto con el mayor centro de la época en el entorno del Xúquer: La Solana del Castell, futura Saitabi. La existencia del punto de recepción e intercambio de mercancías que debió de significar L'Alter de la Vintihuitena, situado al borde de la terraza fluvial del Xúquer al pie de su estuario de desembocadura, fue crucial para que estos navegantes accediesen a las tierras interiores valencianas. No llegaron necesariamente desde La Fonteta, sino que es factible que intentasen evitar el difícil paso del Cabo de la Nao e hiciesen escala en el «comptoir» de Sa Caleta en Ibiza (Ramon, 2007) desde donde es fácil navegar hasta el claro hito geográfico que significa el promontorio de Cullera. Las ánforas de vino mayoritariamente de factura fenicia occidental y la vajilla de barniz rojo, son muy similares a la que se ha documentado en La Fonteta (Rouillard, Gailledrat y Sala, 2007; González Prats, 2011 y 2014). Pero esto ya es otra historia, que abordaremos en un futuro trabajo.

\author{
Prof. Dr. José Pérez Ballester \\ Dpto. Prehistoria y Arqueología \\ Facultad de Geografía e Historia \\ Avda. Blasco Ibáñez, 28 \\ 46010 Valencia \\ jose.perez-ballester@uv.es
}

\section{BIBLIOGRAFIA}

ABARQUERO MORAS, F.J., 2005: Cogotas I. La difusión de un tipo cerámico durante la Edad del Bronce, Arqueología en Castilla y León, 4.

ARRIBAS, A., PAREJA, E., MOLINA, F., ARTEAGA, O. y MOLINA, F., 1974: Excavaciones en el poblado de la Edad del Bronce "Cerro de la Encina», Monachil, Granada, Excavaciones Arqueológicas en España 81, Madrid.

ARTEAGA, O. y SERNA, M.R., 1975: «Los Saladares-71», Noticiario Arqueológico Hispánico Arqueología, 3, 7-140.

ARTEAGA, O., 1982: «Los Saladares-80», Huelva Arqueológica, 6, 131-184.

AUBET, M.E., 1975: La necrópolis de Setefilla en Lora del Río, Sevilla, II, Barcelona.

BARRACHINA IBÁÑEZ, A., 1987: «El Bronze Final del Puig d'Alcoi», Fonaments, 6, 131-156.

BARRACHINA IBÁÑEZ, A., 2012: Indesinenter: Permanencia y cambio. el Pic dels Corbs como modelo de interpretación de la Edad del Bronce en el País Valenciano, Publicacions del Servei d'Investigacions Arqueològiques i Prehistòriques, Castelló.

BARRACHINA IBÁÑEZ, A. y GUSI GENER, F., 2004: «Primeros resultados del estudio cerámico de las fases del Bronce Tardío y Final de Orpesa la Vella (Orpesa, Castelló)», en L. HERNÁNDEZ ALCARAZ y M. HERNÁNDEZ PÉREZ (Eds.), La Edad del Bronce en tierras valencianas y zonas limitrofes, Villena.

BELMONTE MAS, D., 2004: «Un conjunto cerámico del Bronce Tardío e inicios del Bronce Final del yacimiento del Tabayá (Aspe, Alicante). Excavaciones arquueológicas de 1987 a 1991. Corte estratigráfico $\mathrm{n}^{\circ} 11 »$, en L. HERNÁNDEZ ALCARAZ y M. HERNÁNDEZ 
PÉREZ (Eds.), La Edad del Bronce en tierras valencianas y zonas limitrofes, 333-345, Villena.

BLANCO, A., LUZÓN, J.M. y RUIZ, D., 1970: Excavaciones Arqueológicas en el Cerro Salomón (Riotinto, Huel$v a)$, Anales Univ. Hispalense 4, Sevilla.

BONET ROSADO, H., 1995: El Tossal de Sant Miquel de Llíria. La antigua Edeta y su territorio, València.

CASTRO MARTÍNEZ, P.V., 1994: La Sociedad de los Campos de Urnas en el nordeste de la Peninsula Ibérica. La necrópolis de El Calvari (El Molar, Priorat, Tarragona), B.A.R. Intern. Series, 592, Oxford.

CLAUSELL CANTAVELLA, G., 2004: «El Torrelló del Boverot: del Bronce Medio al comienzo del Hierro», en L. HERNÁNDEZ ALCARAZ y M. HERNÁNDEZ PÉREZ (Eds.), La Edad del Bronce en tierras valencianas $y$ zonas limitrofes, 167-176, Villena.

DE PEDRO MICHÓ, M.J., 1998: La Lloma de Betxí (Paterna, València). Un poblado de la Edad del Bronce, Serie de Trabajos Varios del SIP 94, València.

GARCÍA BORJA, P. y PÉREZ JORDÁ, G., 2012: «Ensayo tipológico para el estudio de cerámica prehistórica del País Valencià. Aplicación a colecciones del Bronce Final», Lucentum, XXXI, 31-59.

GARCÍA BORJA, P. y DE PEDRO MICHÓ, M.J., 2013: «El conjunt arqueològic de l'Edat del Bronze» de l'ArbocerAltet de Palau (La Font de la Figuera, València)», en P. GARCÍA BORJA ET ALII (eds.), El naixement d'un poble. Història i Arqueologia de La Font de la Figuera, 73-84, València.

GIL MASCARELL, M., 1981: «Bronce Tardío y Bronce Final en el País Valenciano», Monografias del Laboratorio de Arqueología de Valencia, 1, 9-39.

GONZÁLEZ PRATS, A., 1979: Excavaciones en el yacimiento protohistórico de la Peña Negra, Crevillente (Alicante), Excavaciones Arqueológicas en España 99, Madrid.

GONZÁLEZ PRATS, A., 1982: «La Peña Negra IV. Excavaciones en el Sector VII de la ciudad orientalizante, 1980-1981», Noticiario Arqueológico Hispánico, 13, 305-418.

GONZÁLEZ PRATS, A., 1983: Estudio arqueológico del poblamiento antiguo de la Sierra de Crevillente (Alicante), Anejo I a la revista Lucentum, Alicante.

GONZÁLEZ PRATS, A., 1985: «La Peña Negra II-III. Campañas de 1978 y 1979», Noticiario Arqueológico Hispánico, 21, 9-155.

GONZÁLEZ PRATS, A., 2002: La necrópolis de cremación de Les Moreres, Alicante.

GONZÁLEZ PRATS, A. (Coord. y Ed.), 2011: La Fonteta: excavaciones de 1996-2002 en la colonia fenicia de la actual desembocadura del río Segura, Guardamar del Segura, Alicante, vol. 1, Alicante.

GONZÁLEZ PRATS, A. (Cord. y Ed.) 2014: La Fonteta-2. Estudio de los materiales arqueológicos hallados en la colonia fenicia de la actual desembocadura del río Segura (Guardamar del Segura, Alicante), vol. 1, Alicante.

GONZÁLEZ PRATS, A. y RUIZ SEGURA, E., 1992: «Un poblado fortificado del Bronce Final», Estudios de Arqueología ibérica y romana, Homenaje a Enrique Pla, Trabajos Varios del SIP 89, 17-27 Valencia.

GRAU MIRA. I. y SEGURA MARTÍ, J.M., 2013: El Oppidum ibérico de el Puig d'Alcoi: asentamiento y paisaje en las montañas de la Contestania, Alcoi.

HERNÁNDEZ CARRIÓN, E. y GIL GONZÁLEZ, F., 2004: «La necrópolis del Bronce Final del Collado y Pinar de Santa Ana de Jumilla (Murcia)», en L. HERNÁNDEZ ALCARAZ y M. HERNÁNDEZ PÉREZ (Eds.), La Edad del Bronce en tierras valencianas y zonas limitrofes, 441-454, Villena.

HERNÁNDEZ PÉREZ, M., 2005: «La Contestania ibérica desde la Prehistoria», en 1. Abad, F. Sala y I. Grau (Eds.), La Contestania Ibérica. Treinta años después, 17-36, Alicante.

HERNÁNDEZ PÉREZ, M. y LÓPEZ MIRA, J.A., 1992: «Bronce Final en el Medio Vinalopó. A propósito de dos conjuntos cerámicos del Tabaià (Aspe, Alicante)», Estudios de Arqueología ibérica y romana. Homenaje a Enrique Pla, Trabajos Varios del SIP 89, 1-17, Valencia.

IBORRA ERES, M.P., 2004: La ganadería y la caza desde el Bronce Final hasta el Ibérico Final en el territorio valenciano, Trabajos Varios del SIP 103, Valencia.

LÓPEZ CACHERO, F.J., 2006: Aproximació a la societat del nord-est peninsular durant el bronze final i la primera edat del ferro. El cas de la necrópolis de Can PiteuCan Roqueta (Sabadell, Vallés Occidental, Barcelona), Societat Catalana d'Arqueologia, Barcelona.

LÓPEZ CACHERO, F.J., PONS, E., 2007: «La periodització del bronze final al ferro inicial a Catalunya», Cypsela, 17, 51-64.

LORRIO, A.J., 2008: QURÉNIMA. El Bronce Final del Sureste de la Península Ibérica, Madrid.

MARTÍ OLIVER, B., DE PEDRO MICHÓ, M.J., 1997: «Sobre el final de la Cultura del Bronce Valenciano: problemas y progresos», Saguntum, 30, 59-91.

MARTÍNEZ GARCÍA, J.M., CHÁFER, G. y ESPÍ, I., 2001: «Materiales de la primera Edad del Hierro en la plaza del Castillo de Requena (Valencia): un avance», en A. LORRIO (Ed.), Los iberos en la comarca de RequenaUtiel, Anejos de Lucentum 4, 117-128.

MARTÍNEZ PADILLA, C. y BOTELLA, M.C., 1980: El Peñón de la Reina (Alboloduy, Almería), Excavaciones Arqueológicas en España 116, Madrid.

MATA PARREÑO, C., 1991: Los Villares (Caudete de las Fuentes, Valencia). Origen y evolución de la Cultura Ibérica, Serie de Trabajos Varios del SIP 88, València.

MATA PARREÑO, C. y BONET ROSADO, H., 2001: «Organización del territorio y poblamiento en el País Valenciano entre los siglos VII al II a.C», en L. BERROCAL y Ph. GARDES (Eds.), Entre Celtas e Iberos, 175-186, Madrid.

MATA PARREÑO, C., MARTÍ, M.A. y IBORRA, M.P., 1996: «El País Valencià del Bronze Recent a l'Ibèric Antic: el procés de formació de la societat urbana ibérica», Gala, 3-5, (1994-1996), 183-217.

MESADO OLIVER, N., 1974: Vinarragell (Burriana, Castellón), Trabajos Varios del SIP 46, Valencia. 
MOLINA, F.A., 1999: «La cerámica del Bronce Tardío e inicios del Bronce Final en el Valle Medio del río Vinalopó: el ejemplo del Tabayá (Aspe, Alicante)», Revista d'Arqueologia de Ponent, 9, 117-130.

OLIVER FOIX, A., 1993: «El desarrollo cultural protohistórico en el llano litoral del Maestrat (Castellón)», Cuadernos de Prehistoria y Arqueología Castellonenses, 20, 147-170.

ORTIZ TEMPRADO, R., 2014: «La cerámica a mano», en A. GONZÁLEZ PRATS (Ed.), La Fonteta-2, vol. 1, 13238, Alicante.

PELLICER, M. y SCHÜLE, W., 1966: El Cerro del Real (Galera, Granada), Excavaciones Arqueológicas en España 52, Madrid.

PEÑA SÁNCHEZ, J.L., ENRIQUE TEJEDO, M., GRAU ALMERO, E. y MARTÍ BONAFÉ, M.A., 1996: El Poblado de La Mola d'Agres, València.

PÉREZ BALLESTER, J., (Coord.) 2008: «Arqueología», en Historia de Xàtiva, vol. II, 255-346, València.

PÉREZ BALLESTER, J. y BORREDÁ MEJÍAS, R., 1998: «El poblamiento ibérico del Valle del Canyoles. Avance sobre un proyecto de evolución del paisaje en la comarca de La Costera (Valencia)», Saguntum, 31, 133-152.

PÉREZ BALLESTER, J. y BORREDÁ MEJÍAS, R., 2008: «El territorio y el poblamiento ibérico de Saitabi», en V. VILLAVERDE, J. PÉREZ BALLESTER y A. LEDO, Prehistoria, Arqueología y Antigüedad. Historia de Xàtiva, vol. II, 269-285, Xàtiva.

PÉREZ BALLESTER, J., VELASCO, A., BORREDÁ, R. y RODRÍGUEZ TRAVER, J.A., 2008: «Excavaciones arqueológicas en «La Solana del Castell (Xàtiva)» Campaña de 2007», Saguntum, 39,189-192.

PÉREZ BALLESTER, J., VELASCO, A., BORREDÁ, R. y RODRÍGUEZ TRAVER, J.A., 2009: «Excavaciones arqueológicas en el solar de la antigua Saitabi (La Solana del Castell, Xàtiva). Campaña de 2008», Saguntum, 40, 237-242.

PÉREZ BALLESTER, J., VELASCO, A., BORREDÁ, R. y RODRÍGUEZ TRAVER, J.A., 2010: «Excavaciones en La Solana del Castell (Xàtiva). Campaña de 2009», Saguntum, 42, 111-114.

PÉREZ BALLESTER, J., VELASCO, A., BORREDÁ, R. y RODRÍGUEZ TRAVER, J.A., 2011: «La Solana del Castell (Xàtiva). Campaña de 2010», Saguntum, 43, 199-204.

PÉREZ BALLESTER, J., VELASCO, A., BORREDÁ, R. y RODRÍGUEZ TRAVER, J.A., 2013: «Campañas de excavaciones de 2011 y 2012 en La Solana del Castell (Xàtiva)», Saguntum, 45, 243-246.

PÉREZ JORDÀ G., IBORRA, M.P., GRAU, E., BONET, H. y MATA, C., 2000: «La explotación agraria del territorio en época ibérica: los casos de Edeta y Kelin», en Els productes alimentaris d'origen vegetal a l'edat del Ferro de l'Europa Occidental: de la producció al consum, Serie Monogràfica 18, Museu Arqueològic de Catalunya, Girona.

PICAZO, J.V. y RODANÉS, J.M., 2009: Los poblados del Bronce Final y Primera Edad del Hierro. Cabezo de la Cruz (La Muela, Zaragoza), Gobierno de Aragón, Zaragoza.

PONS, E. y MAYA, J.L., 1988: «L'Âge du Bronze Final en Catalogne», en P. BRUN y C. MORDANT, Le groupe Rhin-Suisse-France orientale et la notion de civilisations des Champs d'Urnes, Colloque de Nemours (1986), 545-558, Nemours.

QUIXAL SANTOS, D., 2012: «El Valle del río Magro como vía de comunicación en época ibérica (siglos VI-I a.C.)», Archivo de Prehistoria Levantina, XXIX, 187-208.

RAMON TORRES, J., 2007: Excavaciones arqueológicas en el asentamiento fenicio de Sa Caleta (Ibiza), Cuadernos de Arqueología Mediterránea, 16, Barcelona.

ROS SALA, M., 1989: La pervivencia del elemento indigena: La cerámica ibérica, Serie La ciudad romana de Carthago Nova: Fuentes y materiales para su estudio 1, Murcia.

ROUILLARD, P., GAILLEDRAT, E. y SALA, F., 2007: L'établissement protohistórique de La Fonteta (fin VIII - fin VI siècle av. J.-C.), Coll. Casa de Velázquez 96, Madrid.

RUIZ MATA, D., FERNÁNDEZ JURADO, J. ET ALII, 1986: El yacimiento metalúrgico de época tartésica de San Bartolomé de Almonte (Huelva), Huelva Arqueológica, 8,2 vols.

RUIZ ZAPATERO, G., 1985: Los Campos de Urnas del NE de la Península Ibérica, 2 vols. Tesis Doctoral reprografiada, Ed. de la Universidad Complutense de Madrid.

RUIZ ZAPATERO, G., 2007: «Antes del Hierro. Cultura y Sociedad en el centro de la Meseta (ca. 1200-500 a.C.)», en A.F. DÁVILA (Ed.), Estudios sobre la Edad del Hierro en la Carpetania, vol. I, 36-63, Alcalá de Henares.

SIMÓN GARCÍA, J.L., 1997: «La Illeta: Asentamiento litoral en el Mediterráneo Occidental en la Edad del Bronce», en M. OLCINA DOMÉNECH (Ed.), La Illeta dels Banyets (El Campello, Alicante). Estudios de la Edad del Bronce y Época Ibérica, Serie Mayor, 1, 47-131, Alicante.

SORIA, L., MATA, C., 2002: «Cerámicas a mano con decoración incisa del Bronce Final / Hierro Antiguo al norte del Júcar (La Manchuela, Albacete)», Anales de Prehistoria y Arqueología, 17, 95-108.

VILASECA, S., 1969: «La Cueva de la Font Major», Trabajos de Prehistoria, XXVI, 117-220.

VIVES FERRÁNDIZ, J., 2006: Negociando Encuentros. Situaciones coloniales e intercambios en la costa oriental de la península Ibérica (ss. VIII-VI a.C.), Cuadernos de Arqueología Mediterránea, 12, Barcelona. 